PB 250666

NBSIR $76-834$

AFCRL-TR-76-0012

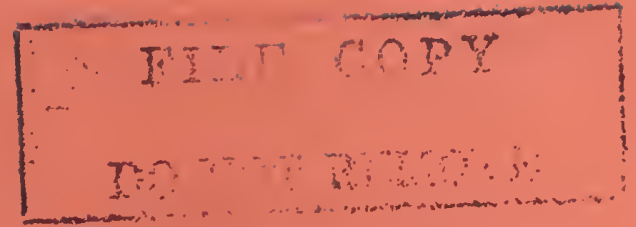

\title{
A SYSTEM FOR INFLATING A BALLOON USING HELIUM STORED IN THE LIQUID PHASE
}

C. F. Sindt

W. R. Parrish

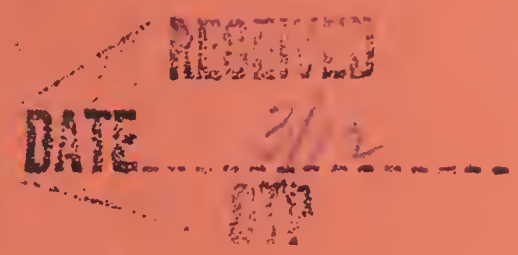

Cryogenics Division

Institute for Basic Standards

National Bureau of Standards

Boulder, Colorado 80302

January 1976

Prepared for :

Air Force Cambridge Research Laboratories

Air Force Systems Command

United States Air Force

Hanscom AFB, Massachusetts 01731 



\section{NBSIR $76-834$ \\ AFCRL-TR-76-0012}

\section{A SYSTEM FOR INFLATING A BALLOON USING HELIUM STORED IN THE LIQUID PHASE}

C. F. Sindt

W. R. Parrish

Cryogenics Division

Institute for Basic Standards

National Bureau of Standards

Boulder, Colorado 80302

January 1976

Prepared for:

Air Force Cambridge Research Laboratories

Air Force Systems Command

United States Air Force

Hanscom AFB, Massachusetts 01731

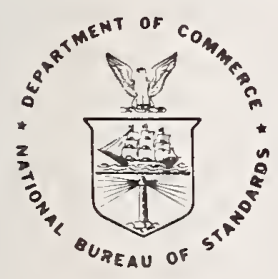

U.S. DEPARTMENT OF COMMERCE, Rogers C. B. Morton, Secretary James A. Baker, III, Under Secretary Dr. Betsy Ancker-Johnson, Assistant Secretary for Science and Technology 
REPORT DOCUMENTATION PAGE

REA D INSTRUCTIONS

\begin{tabular}{|c|c|}
\hline REPORT DOCUMENTATIOH PAGE & $\begin{array}{l}\text { READ INSTRUCTIONS } \\
\text { BEFCRE COMPLETING FORM }\end{array}$ \\
\hline $\begin{array}{l}\text { 1. REPORT NUMIER } \\
\text { AFCRL-TR-76-0012 }\end{array}$ & 3. PECTOERT'S CATALOG NUMBER \\
\hline \multirow{2}{*}{$\begin{array}{l}\text { 4. TITLE (and Subtt10! } \\
\text { A SYSTEM FOR INFLATING A BALLOON } \\
\text { USING HELIUM STORED IN THE LIQUID } \\
\text { PHASE }\end{array}$} & $\begin{array}{l}\text { 5. TIFE OEPCRT PEAIOD COVEREE } \\
\text { Scientific. Interim. }\end{array}$ \\
\hline & $\begin{array}{l}\text { 6. PERFOFMING ORG. REPORT NUMBER } \\
\text { NBSIR } 76-834\end{array}$ \\
\hline \multirow{2}{*}{$\begin{array}{l}\text { 7. AUTHOR(o) } \\
\text { C. F. Sindt } \\
\text { W.R. Parrish }\end{array}$} & 8. CONTRACT OR GRANT NUMBER(s) \\
\hline & $\mathrm{N} / \mathrm{A}$ \\
\hline $\begin{array}{l}\text { 9. PERFORMING ORGANIZATION NAME AND ADORESS } \\
\text { CryogenicS Division } \\
\text { Institute for Basic Standards } \\
\text { National Bureau of Standards } \\
\text { Boulder, Colorado } 80302 \\
\end{array}$ & 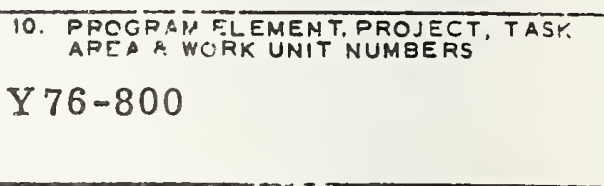 \\
\hline $\begin{array}{l}\text { 11. CONTROLLING OFFICE NAME AND ADORESS } \\
\text { Air Force Cambridge Research Laboratories } \\
\text { Hanscom AFB, Massachusetts } 01731 \\
\text { Monitor/Andrew S. Carten, Jr./LCH }\end{array}$ & 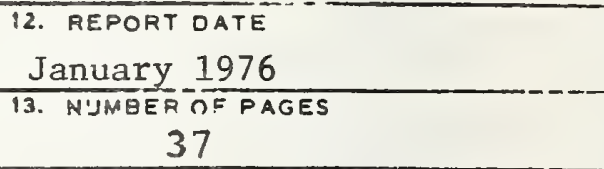 \\
\hline \multirow[t]{2}{*}{ 14. MONITORING AGENCY NAME \& ADORESS(It dilferent from Controlline Offico) } & $\begin{array}{l}\text { 15. SECURITY CLASS. (of th/s report) } \\
\text { Unclassified }\end{array}$ \\
\hline & $\begin{array}{l}\text { 15. DECLLASSIFICATION'DOWNGRADING } \\
\text { SCHEDULE }\end{array}$ \\
\hline
\end{tabular}

16. DISTRIBUTION STATEMENT (OI thi Roport)

Approved for public release; distribution unlimited.

17. DISTRIBUTION STATEMENT (of the abotract onlesed in Block 20, If different from Ropost)

18. SUPPLEIAENTARY NOTES

19. KEY WORDS (Continue on teverse side if neceesary and identily by block number)

Balloon

Cryogenic balloon inflation

Heat transfer

Liquid helium

Packed bed heat exchangers

20. ABSTRACT (Continue on soverso side il necossory and identlfy by block number)

This report covers the design and development of the prototype of a system to be used to fill a balloon that has been launched from an aircraft. The described system uses a hot packed bed heat exchanger to gasify $45.4 \mathrm{~kg}$ of liquid helium and warm the gas to $260 \mathrm{~K}$ for filling the balloon. The prototy: system was successfully demonstrated on the ground by filling an ambient pressure balloon with $300 \mathrm{~m}^{3}$ of helium gas at an average temperature of $260 \mathrm{~K}$ in six minutes and 45 seconds. 
1. INTRODUCTION . . . . . . . . . . . . . . . . . . . . . . . 1

2. AIR-LAUNCHED BALloON SYSTEM DESIGN OBJECTIVES . . . . . . . . . . . . . . 2

3. EVALUATION OF PROPOSED SYSTEMS . . . . . . . . . . . . . . . . . . 3

4. REDUCED SCALE TESTS AND MATHEMATICAL MODELS . . . . . . . . . . . . . . . 4

4.1 Helium Dewar Performance . . . . . . . . . . . . . . . . . 4

4.2 Removing Helium from the Dewar ................ . 5

4.3 Thermal Shock Test of the Bed Media . . . . . . . . . . . . . . . 8

4.4 Modeling and Experimental Test of the Small Scale Heat Exchanger . . . . . . 9

4.4.1 Modeling the Packed Bed Heat Exchanger . . . . . . . . . . . 9

4.4.1.1 The Mathematical Model . . . . . . . . . . . 9

4.4.1.2 Determination of Heat Transfer Coefficients . . . . . . 10

4.4.1.3 Nomenclature ............... . . 11

4.4.2 Test Program for the Small Scale Heat Exchanger . . . . . . . . . 11

5. DESIGN OF THE FULL SCALE SYSTEM . . . . . . . . . . . . . . . . . . 14

6. INSTRUMENTATION . . . . . . . . . . . . . . . . . . . . . 18

7. FULL SCALE TEST PROGRAM . . . . . . . . . . . . . . . . . . . . 19

7.1 Startup Transient and Valve Timing Tests . . . . . . . . . . . . . . 19

7.2 Testing of the Packed Bed and the Gas Mixer . . . . . . . . . . . 20

8. FILling THE BALLOON . . . . . . . . . . . . . . . . . . . . . 24

9. DISCUSSION OF THE EXPERIMENTAL SYSTEM . . . . . . . . . . . . . . . . 24

9.1 Insulation in the Hot Bed Discharge Tube . . . . . . . . . . . . . . . 24

9.2 ALBS System Weight . . . . . . . . . . . . . . . . . . 24

10. CONCLUSIONS . . . . . . . . . . . . . . . . . . . . . . 31

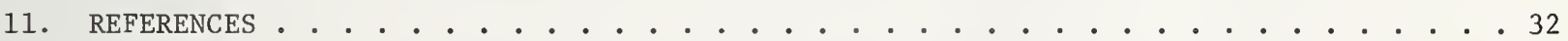

\section{LIST OF FIGURES}

Figure 1. Air-Launched Balloon System (ALBS) . . . . . . . . . . . . . 2

Figure 2. Blow-down characteristics of a dewar of saturated liquid helium . . . . . 6

Figure 3. The mass discharged by the blow-down of a dewar of supercritical and saturated liquid helium ................... 7

Figure 4. Schematic of an ALBS using dewar blow-down for liquid removal . . . . . . 8

Figure 5. Schematic of an ALBS using warm gas pressure for liquid remova1 . . . . . 9

Figure 6. Aluminum oxide spheres used for the hot bed media . . . . . . . . . . 12

Figure 7. Schematic of reduced scale hot bed test apparatus . . . . . . . . . . 13

Figure 8. Bed discharge temperature vs. time, predicted and test data. . . . . . . 14

Figure 9. Hot bed inner vessel ... . . . . . . . . . . . . . . 16

Figure 10. Hot bed inner vessel with the insulation blanket . . . . . . . . . . 17

Figure 11. Cross section of the heat exchanger assembly . . . . . . . . . . . 18

Figure 12. Typical data printout from the test program . . . . . . . . . . . . 19

Figure 13. Louvered gas mixer . . . . . . . . . . . . . . . . . . 21

Figure 14. Schematic of the ALBS experimental unit . . . . . . . . . . . . . 22

Figure 15. ALBS heat exchanger and plumbing ................. 23 
Figure 16. ALBS before the demonstration filling of the balloon . . . . . . . . . 25

Figure 17. The cold gas plumbing during the filling of the balloon . . . . . . . . . 26

Figure 18. The filled balloon . . . . . . . . . . . . . . . . . . . . . 27

Figure 19. Discharge tube insulation using powder on a butterf1y va1ve . • . . . . . . 28

Figure 20. Discharge tube insulation using contained powder on a burst disc . . . . . . 29

Figure 21. Discharge tube insulation using a moving fiber plug . . . . . . . . . . 30

\section{LIST OF TABLES}

Table 1. Selected Properties of Aluminum Oxide and Beryl1ium Oxide . . . . . . . . 4

Table 2. ALBS Weights . . . . . . . . . . . . . . . . . . . . . 31 
A SYSTEM FOR INFLATING A BALLOON USING HELIUM STORED IN THE LIQUID PHASE广

C. F. Sindt and W. R. Parrish

Cryogenics Division

Institute for Basic Standards

National Bureau of Standards

Boulder, Colorado 80302

Abstract

This report covers the design and development of the prototype of a system to be used to fill a balloon that has been launched from an aircraft. The described system uses a hot packed bed heat exchanger to gasify $45.4 \mathrm{~kg}$ of liquid helium and warm the gas to $260 \mathrm{~K}$ for filling the balloon. The prototype system was successfully deanstrated on the ground by filling an ambient pressure balloon $\bar{k}-t h 300 \mathrm{~m}^{3}$ of heliur gas at an average temperature of $260 \mathrm{~K}$ in six minutes and 45 seconds.

Key words: Balloon; cryogenic balloon inflation; heat transfer; liquid helium; packed bed heat exchangers.

\section{INTRODUCTION}

Balloons have been used by man since late in the 18th century and are still used extensively for military applications, for atmospheric observations and for recreatica. Launching a balloon has historicaily required low ground winds, hours of preparation and a favorable launching site. Placing a balloon and its payload at a desired location at a specific time requires considerable planning combined with satisfactory atmospheric conditions. Some of these restraints were overcome by Payne [1] in the late 1950's and early 1960's when he successfully launched a small balloon from a flying aircraft; hovever, the growth of his balloon system was restricted because of the very heavy compressed gas storage tanks used for the inflating gas.

In the last few years the Air Force has been investigating the feasibility of launching large balloons from aircraft because of a potential application in supporting ccmunication relay platforms. The Air Force has established a project to advance the technology needed to develop a successful system. A report on this project by Carten [2] describes the system concept and covers several methods of inflating and deploying balloons from aircraft and rockets. The aircraft launching system described by Carten is depicted in figure 1.

Carten's investigation indicated the most desirable method of providing inflating gas for the Air-Launched Balloon System (ALBS) is to use either liquid helium or liquid hydrogen, to convert it to gas and to heat it to a temperature acceptabie to the balloon. This method takes advantage of the low volume and pressure of the liquid phase, but it does require a heat source and a large heat transfer rate between the inflating gas and the heat source.

The Cryogenics Division of the National Bureau of Standards was called upon to develop an experimental system that would convert liquid hydrogen or helium to gas in a short time and to demonstrate that the system could eventually be used to fill a balloon in mid-air. This report covers the work at the Cryogenics Division from the preliminary evaluation to the first demonstration filling of a balloon on the ground.

This work was jointly sponsored by the Air Force Cambridge Research Laboratories and the Electronics Systems Division (AFSC), Hanscom Air Force Base, Bedford, Massachusetts 01731 , under Air Force Project Order Numbers Y74-898, Y75-808,-841, Y76-800. 


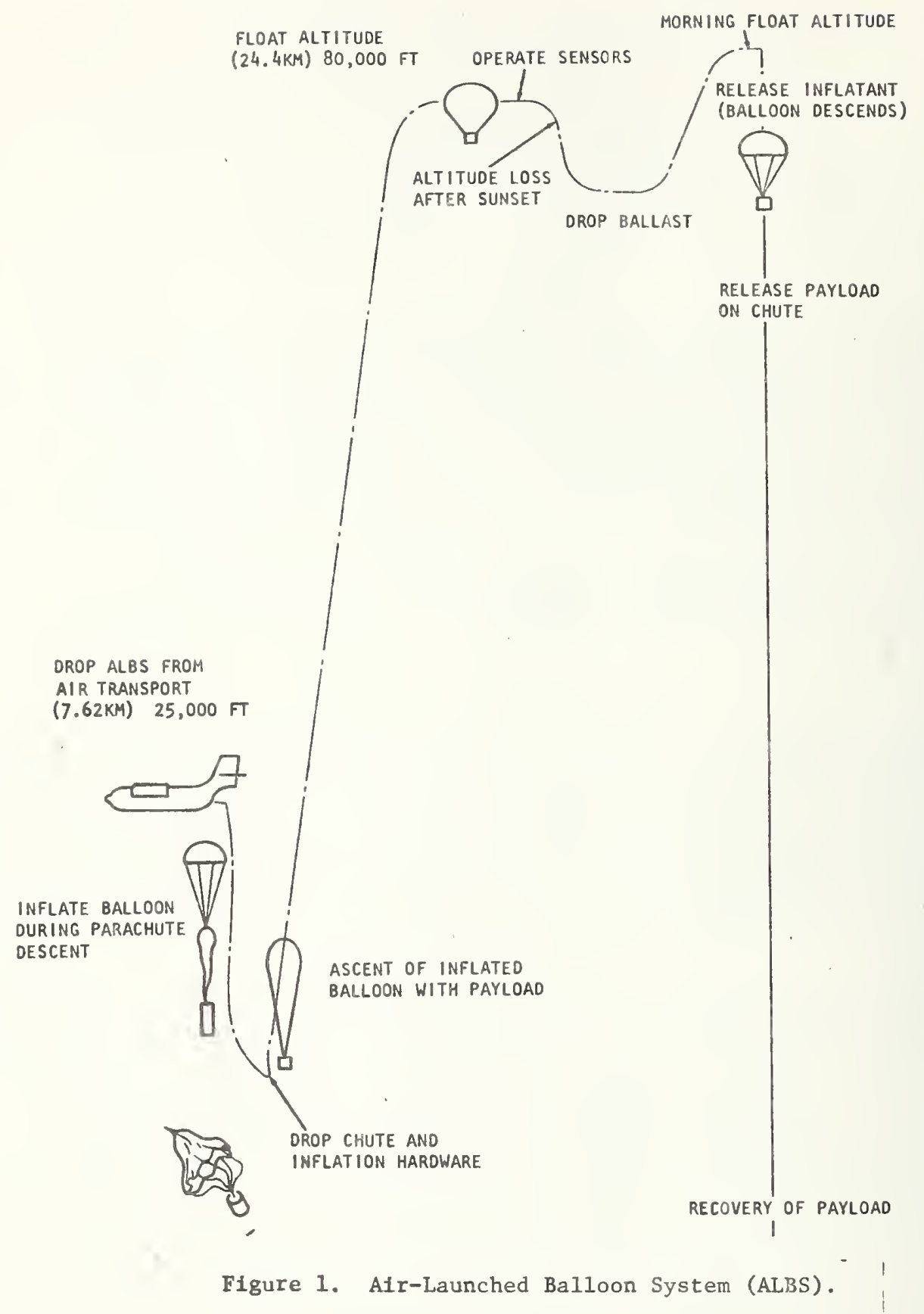

\section{AIR-LAUNCHED BALLOON SYSTEM DESIGN OBJECTIVES}

At first liquid hydrogen and liquid helium were both considered as a possible source for the gas to inflate the balloon. Liquid hydrogen was excluded eariy in the program because of the logistics of handling a combustible liquid and because the combustible liquid and venting gas needed to be in close proximity to a high temperature device required for liquid conversion. After the decision was made to use helium, the program effort was then directed toward selection of a system for liquid helium storage and for conversion of the liquid to gas. The criteria established for the program were:

1. To convert $45.4 \mathrm{~kg}$ of liquid helium to gas;

2. To produce gas at a temperature between 218 and $323 \mathrm{~K}$, with an average gas temperature of 220 to $260 \mathrm{~K}$; 
3. To complete the entire process (vaporization, gas warming, balloon inflation) in five minutes;

4. To package the system in a cylinder $91 \mathrm{~cm}$ in diameter by $166 \mathrm{~cm} 1 \mathrm{ong}$ and have it weigh $160 \mathrm{~kg}$.

Using these criteria the heat required to convert the liquid to gas and heat it to $260 \mathrm{~K}$ was between $5.3 \times 10^{7}$ and $6 \times 10^{7} \mathrm{~J}$ and the heat transfer rate had to be between 177 and $200 \mathrm{~kW}$.

From these general criteria, the following design objectives were established:

1. The system must store $45.4 \mathrm{~kg}$ of helium in the minimum space with minimum weight for a period of four to seven days without refilling or other service.

2. The system must be instantly ready to supply helium to the balloon at a continuous flow rate of $0.16 \mathrm{~kg}$ per second and at an average temperaicure of 220 to $260 \mathrm{~K}$.

3. For the first 30 seconds, the flow rate is to be approximately one half of the average rate.

4. The system must be compatible with the environment in a nonpressurized aircraft and must operate in the ambient conditions between sea level and $7.6 \mathrm{~km} \mathrm{altitude.}$

5. It must withstand the shock loads incurred in cargo aircraft operations, in the opening of a parachute, and in the landing by parachute.

6. It must be refurbishable after the parachute landing.

The size and weight specifications given by Carten [2] were established as design objectives but were not rigid criteria, especially for the experimental unit. Yowever, the objectives of lightweight and compactness were still valid anc although the actual experimental hardware didn't need to meet these objecives, the system concept had to be compatible with them.

\section{EVALUATION OF PROPOSED SYSTEMS}

Several systems discussed by Carten for gasifying and warming helium were evaluated in a preliminary study along with a preliminary look at high pressure gas storage. The systems considered for converting the liquid helium to warm gas used heat exchange with the following: 1) hot gas from a gas generator, 2) a packed bed heat exchanger and 3 ) an electric heater. The types of gas generators considered were those using fuel and air, fuel and an oxidizer and a single component such as a solid rocket motor uses. All of the gas generators have a similar system requirement; they must transfer heat between the hot gas and the helium at a rate of $190 \mathrm{~kW}$. This requires a very large, heavy unit. Instead of using a large heat exchanger the hot gas from the generator could be mixed directiy with the helium. This method has the disadvantage of adding gas to the balloon that is heavier than air and, therefore, adds to the total weight and required balloon volume. Also, some products of combustion from the gas generators, such as water, will freeze out at the desired gas temperature and may endanger the balloon material or interfere with the filling of the balloon. Gas generators that burn fue 1 and air or oxidizers are in general complex, requiring pumps, controls, etc. and are therefore expensive.

Electrical heating was considered only briefly but was rejected because there is no means of storing the required electrical energy in a package that is compatible with the objectives of light weight.

A high pressure gas storage system was considered, as advances in high pressure cylinder design have been made since Payne's time; however, this system was still four times heavier than the desired maximum weight.

The storage of heat in a packed bed using direct heat exchange with the helium was then evaluated considering a number of materials for heat storage. Material selection was based on a number of criteria. High specific heat was an obvious requirement; high specific weight was also desired to keep the volume within the design criteria. Since heat stored in any material is nearly proportional to the temperature, the higher the temperature the more heat stored per unit miss; therefore, the hot bed material had to be compatible with high temperature - that is, it must not break from thermal shock, it must not melt or deform at high temperatures and it must not react chemically with air that may be in the system during the heating of the bed. 
Heavy metals in general filled the requirements of specific weight but they have lower specific heats than some metal oxides; also, some of the heavy metals melt at low temperatures. Some of the metallic sulfates have high specific heats but have other undesirable characteristics such as low melting points or they are corrosive to metal containers.

Two oxides of metals filled all of the desired criteria fairly well. They were aluminum oxide $\left(\mathrm{Al}_{2} \mathrm{O}_{3}\right.$ ) and beryllium oxide $(\mathrm{BeO})$. Both have high specific heat at high temperature, both are compatible with high temperature, neither is highly susceptible to thermal shock as they have low thermal expansion coefficients and neither is degraded by heating in air. Both oxides are in the medium range of specific weights, but because they filled the other criteria, they were selected for further evaluation. Properties for both are given in table 1.

Table 1. Selected Properties of Aluminum Oxide and Beryllium Oxide [3]

\begin{tabular}{|c|c|c|}
\hline Specific Heat & Aluminum Oxide & Bery1lium Oxide \\
\hline at $900 \mathrm{~K}$ & $1.21 \mathrm{~J} /(\mathrm{g} \cdot \mathrm{K})$ & $1.99 \mathrm{~J} /(\mathrm{g} \cdot \mathrm{K})$ \\
\hline at $300 \mathrm{~K}$ & $0.80 \mathrm{~J} /(\mathrm{g} \cdot \mathrm{K})$ & $1.088 \mathrm{~J} /(\mathrm{g} \cdot \mathrm{K})$ \\
\hline Specific Weight & 3.6 to $3.9 \mathrm{~g} / \mathrm{cm}^{3}$ & $3.03 \mathrm{~g} / \mathrm{cm}^{3}$ \\
\hline Melting Point & $2310 \mathrm{~K}$ & $2725 \mathrm{~K}$ \\
\hline
\end{tabular}

After pricing the aluminum oxide and beryllium oxide, the aluminum oxide was selected for the experiment even though beryllium oxide has a higher specific heat. The reasons for selecting aluminum oxide were that it was twelve times less expensive than beryllium oxide and it was readily available in a number of sizes of balls suitable for hot packed bed use.

The packed bed heat exchanger system was selected cver the other systems because of the following advantages: 1) The system is relatively simple as it requires no auxiliary pumps, no complex speed and fluid flow controls and no ignition sources such as required by gas generators. 2) The system does not contaminate the inflating gas as the heat storage media is chemically and physically stable throughout the operating temperature of the hot bed. 3) The preliminary study indicated a weight advantage over systems using gas generators with heat exchangers.

With the type of heat exchanger selected and the rest of the system constraints defined, the system functions to be resolved by analysis or experiment were heat transfer in the hot bed, mixing of the hot gas from the bed with cold gas to get the desired temperature, removing the helium from the dewar and control of the helium flow.

\section{REDUCED SCALE TESTS AND MATHEMATICAL MODELS}

Reduced scale tests were conducted and mathematical models were used early in the investigation to determine the characteristics of certain system functions, such as heat transfer in the hot bed (see 4.4) and liquid helium transfer from the dewar (see 4.2).

Even though mixing of the hot and cold gas stream was considered one of the areas requiring development, no small scale tests or models were set up; instead, the mixer was developed and tested on the full scale experiment conducted later in the investigation. This decision was made because a mixer test required a test fixture as complex as the system for filling a balloon. The mixing experiments are described in section 7 .

\subsection{Helium Dewar Performance}

Since the performance of high quality liquid helium dewars is quite well known, no experimental verification of dewar performance was required. Estimated dewar performance was used to analytically determine the best technique to achieve the desired seven days of liquid storage without service. Two methods of storage were analyzed. 
In the Eirst nethod considered for the helium storage, the liquid helium would be kept at one atmosphere pressure by venting the boiling liquid. In this systen the cold vented gas would be used to cool a thermal radiation shield in the dewar insulation and about one percent of the initial liquid would be boiled away each day. So, by increasing the initial aass by seven percent, an adequate supply of helium would be available to fill the balloon after seven days of storage.

In the second nethod considered for the storage of helium, the dewar would be filled with liquid in equilibrium with one atmosphere pressure, then it would be sealec for the duration of the storage period and the pressure would be allcwed to rise. The pressure would reach 15 atnospheres in six days it the ullage at the tife the dewar nad been filled was ten percent. Fifteen atmospheres pressure was the maxitun pressure considered for the analysis since the weight of the dewar inner vessel became excessive for higher pressures. This method of storage would be suitable for "blowing down" (removing the heliu= from) an ALBS system that has no dewar pressurization scheze (see 4.2) but it zequires that the heliun be in the liquid state at high pressure $c e$ in the supercritical condition.* However, if the system were to be used i-mediately after filling the dewar, pressure would be too low and a device for increasing the pressure would still be neeced, in order to rezove the helium from the dewe:.

In the end, selection of the liquid storage method was based cn the fluid control systet requirements instead of dewar perforzance, as both of the helium storage methods described are feasiole and are "stare-of-the-art" for licuid heitur.

\subsection{Renoving Eelium Frop the Dewar}

The characteristics of renoving liquid heliut froa a cewar were considered as unknown, even though transferring liquid heliu is a daily occurrence. Information on the amount of externally-supplied helium gas required to expel liquid fron a dewar maintained at atmospheric pressure is meager, as is information on the characteristics of blowing-down dewars of supercritical helium cr saturatad licuid helium at eievated pressures.

Snall scale tests were ccrducted to deternine the azount of helium gas needed to pressure transfer saturated liquid helium in equilibriul at one atmosphere pressure. The tests were made realizing that the dewar materials and shape would have a significant effect on the pressurizing gas required; thereiore, test results were just used as a guide.

The experimental apparatus for the pressure cransfer tests included a 50 liter receiving dewar, a heliun gas supply crlinder fitted with a pressura regulator, a 33 liter derar oz liquid helium and a transfer line between the two dewars. The test procedure was to pressurize the liquid helium dewar to approximately $34 \mathrm{kge}$ ( 5 psig); then to aeasure the time required to transfer the 33 liters of liquid helium fron the supply dewar to the receiving devar. The gas consuzed to rransier the 33 liters of liquid ras calculated using an estimated gas temperature-rooz temperature - and the deasurements cE ths pressure in the helium supply cylinder before and after the liquid transfer. All the reasurements were crude since the results were just to be used as a guile. Fro the results o these experiments the minimum quantity of gas required to pressure transfer the required $45.4 \mathrm{~kg}$ of licuid at the rate of $0.16 \mathrm{~kg}$ per second was deternined to be equivalent to $2.6 \mathrm{~m}^{3}$ at standard pressure and temperature.

The blow-down charateristics of a dewar of saturated liguid helium in eçulibrium with pressures up to critical pressure, and of a dewar of suparcritical helium were determined by analytical models instead of tests. Two separate godels were required; one model for the saturated liqquid helium case and one for the supercritical helium case. For saturated liquid heliun the dewar was considered to $b e 100$ percent full of liguid in ecuilibrium at the starting pressure, and the lass discharged was determine for exhaust pressures down to 0.5 atmosphere. The results fron these analyses are shon in figure 2. Also shown in figure 2 for each curve is the ratio $\mathrm{YI}_{\mathrm{M}} \mathrm{M}$, winich is the ratio of the mass of the saturated liquid at the starting pressure to the mass of the licuid required to completely fill the dewar at one atmosphere pressure. This ratio was determined so that all of the syste-s could be compared to a conmon base. Io get the ratio of the mass dischargec to the mass at the co=m base, we must multiply the abscissa of figure 2 by Yil Mo. This ratio was calculated for a discharge pressure of one atmosphere and is shown as curve $A$ on figure 3.

*A fluid that is supercritical is at a temperature and pressure above its critical point. At the critical point the specific volume of gas and liquid becomes equal, and above this point the fluid no longer separates into the liquid and gas phases. Heliu critical temperature and pressure are $5.2014 \mathrm{~K}$ and 2.245 atrospheres respectively. 


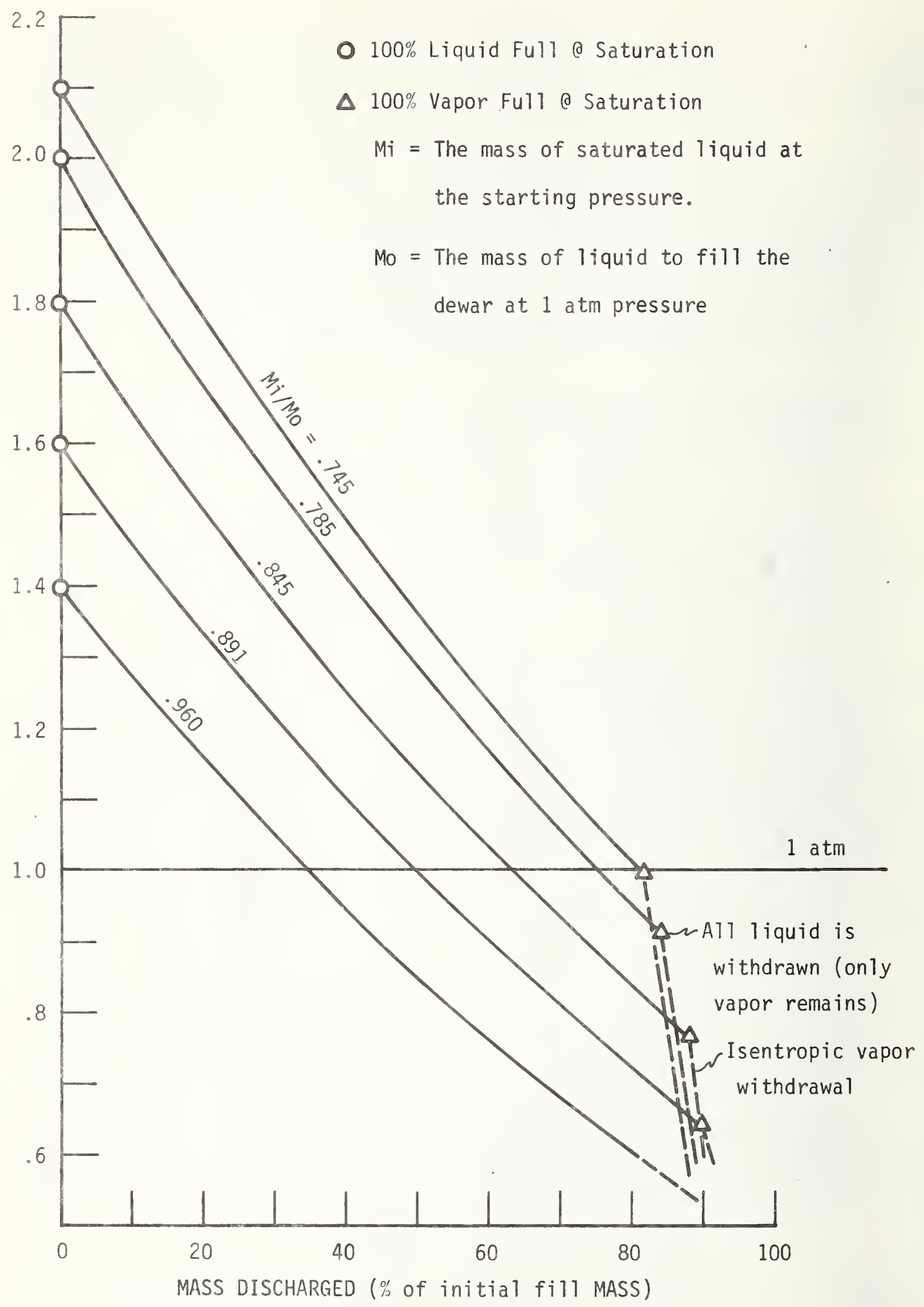

Figure 2. Blow-down characteristics of a dewar of saturated liquid helium. 


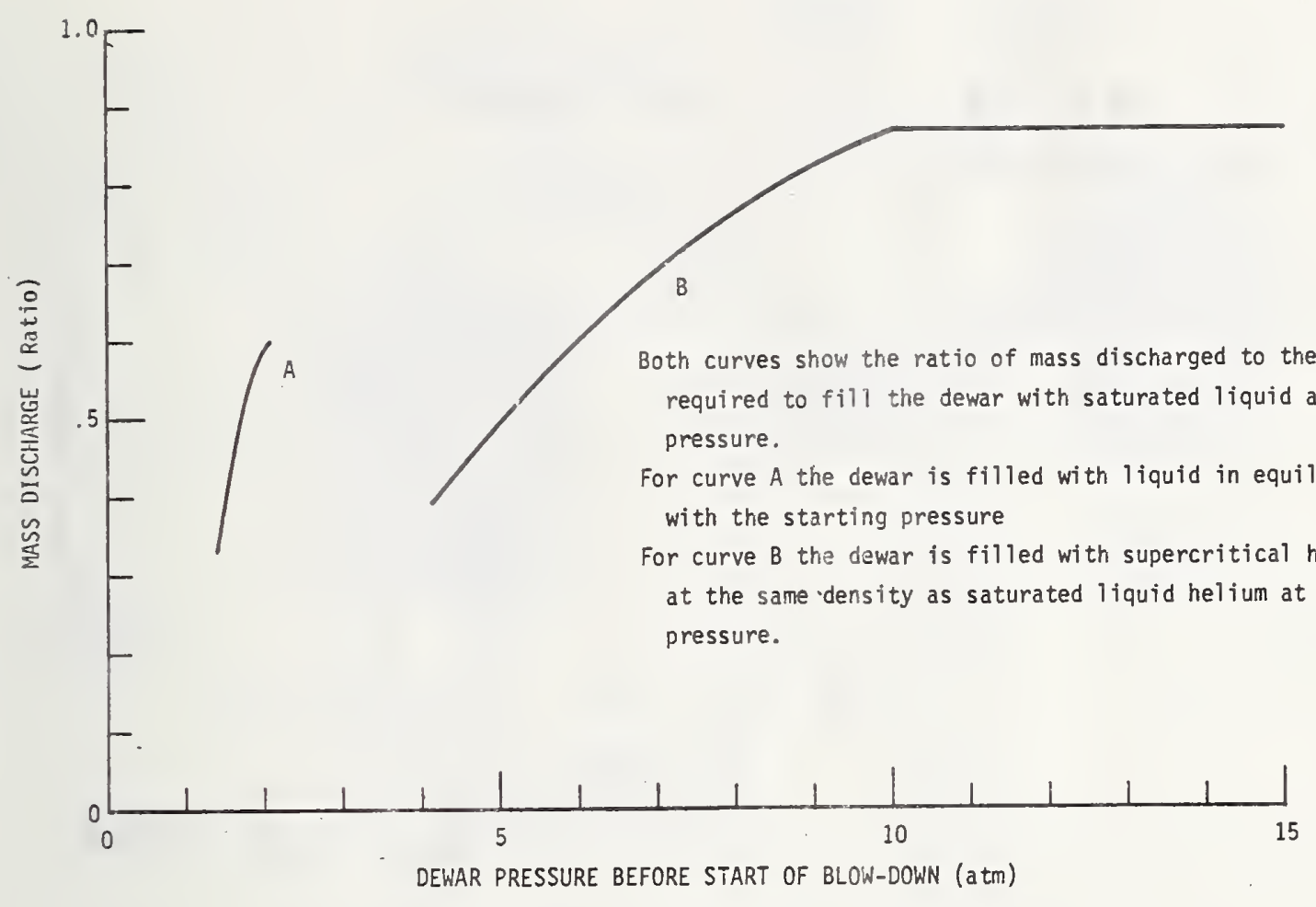

F1gure 3. The mass discharged by the blow-down of a dewar of supercritical and saturated liquid helium.

In the analysis for the blow-down of a dewar of supercritical helium, the dewar was assumed to be filled completely with liquid in equilibrium at one atmosphere. The mass of this liquid is the same mass as the base mass used for the saturated liquid helium analysis. To get supercritical pressure after filling the dewar, heat must be added either by the dewar heat leak or by an externally powered heater. The mass discharged from the dewar of supercritical helium was calculated by assuming an exhaust pressure of one atmosphere. The ratio of discharged mass to the mass used to fill the dewar is shown versus the pressure before the blow-down by curve B of figure 3. Because the ratio of mass discharged from the dewars of supercritical helium and saturated liquid helium was calculated using the same base mass at the same thermodynamic conditions, the curves A and B of figure 3 show a direct comparison based on dewars of equal volume.

It is apparent that little is to be gained by pressures higher than 10 atmospheres $\left(1.013 \times 10^{6} \mathrm{~Pa}\right)$. It is also apparent that the best one can do with this system is to expel 86 percent of the initial mass. So, for a system designed to supply $45.4 \mathrm{~kg}$ of 1 iquid helium, $6.4 \mathrm{~kg}$ of helium are going to remain in the dewar and the dewar must be constructed to contain 10 atmospheres pressure. Both the saturated liquid helium storage and the supercritical helium storage systems require some complexity in valving for flow control to maintain a nearly constant flow rate. A schematic for a blow-down system is shown in figure 4 . The depicted system uses valves opened in a programmed sequence as a means of flow control.

Another method for supplying pressure to discharge the helium from the dewar is to add heat from the hot bed to the liquid in the dewar at a rate to keep the dewar pressure constant during discharge. This method would require less complex controls for the fluid since the dewar pressure is constant. Results of the analysis for this system showed that the 


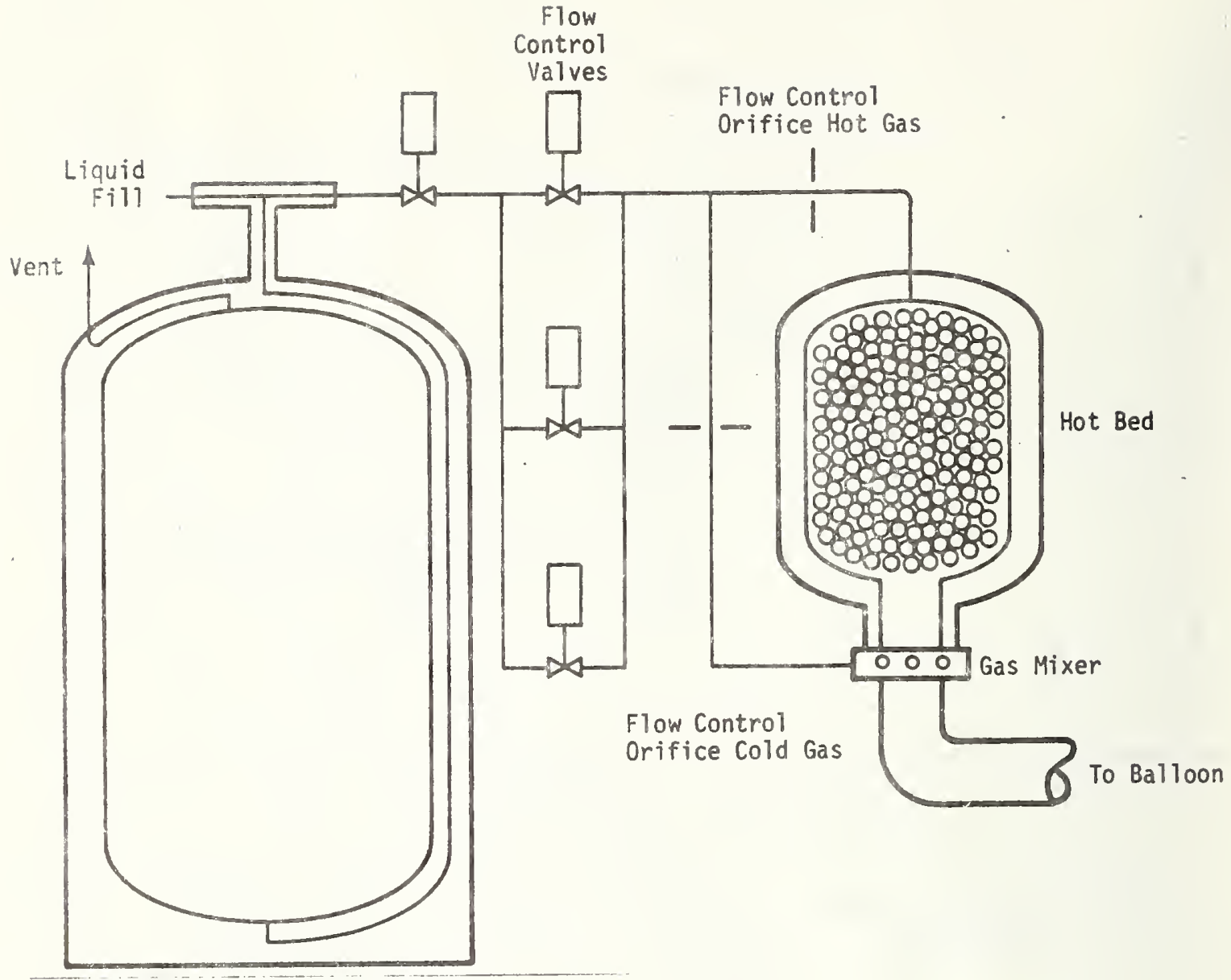

Supercritical Hel fum Dewar

F1gure 4. Schematic of an ALBS using dewar blow-down for liquid removal.

heat flow rate to maintain constant pressure varied four fold in less than four of the five minutes total flow time. It was apparent that this system would also be complicated requiring a pressure controller to operate a throttle valve which would be used to control flow to a heat exchanger in the dewar. The heat exchanger would require two more penetrations through the dewar insulation, thereby reducing storage efficiency.

After considering the described methods of removing the helfum, it was decided to use a gas pressurization system to pressure transfer liquid helium that has been stored at slightly over atmospheric pressure. This system would use a cylinder of high pressure helium gas, a valve and a pressure regulator. This appeared to be the least complicated, most reliable and lightest weight method of those studied for removing helium from the dewar. The system is depicted schematically in figure 5.

\subsection{Thermal Shock Test of the Eed Media}

A simple test was made to determine if the aluminum oxide spheres selected for the hot bed media would stand the shock of the thermal cycle when cold helium gas flowed onto a bed at $1090 \mathrm{~K}$. The spheres were heated to red hot, we11 above $1090 \mathrm{~K}$, and dropped into a dewar of liquid nitrogen. This test was conducted on three spheres for three times with no evidence of fracture. The spheres were subsequently dropped on a concrete floor from a height of one meter and none broke. Thus it was assumed that they would withstand the thermal shock experienced in the hot bed. 


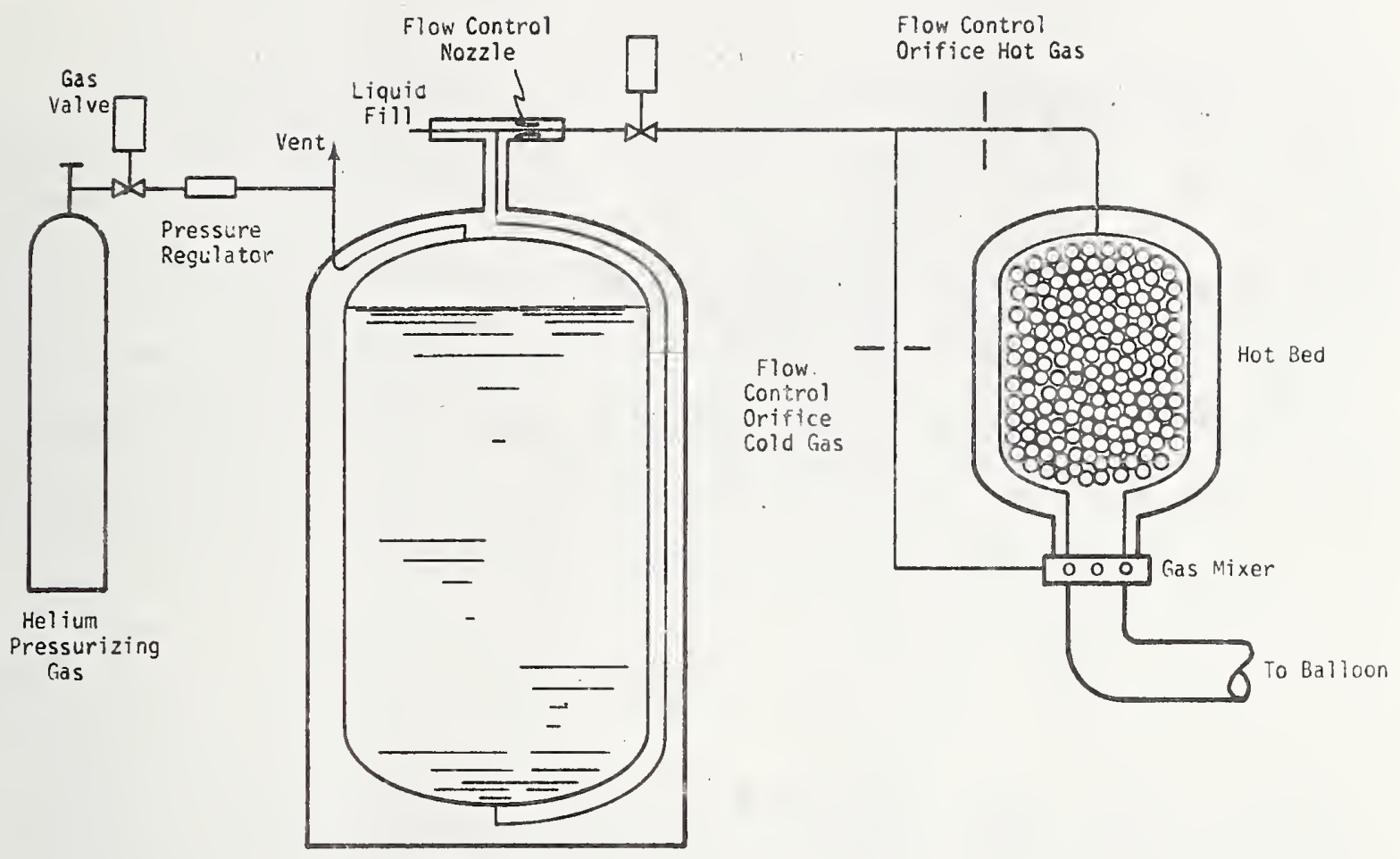

Liquid Helium Dewar

Figure 5. Schematic of an ALBS using warm gas pressure for liquid removal.

\subsection{Modeling and Experimental Test of the Small Scale Heat Exchanger}

A test program was combined with a mathematical model to determine the heat transfer characteristics of the packed bed heat exchanger. Results from model and tests were to be used to design the full scale heat exchanger and to determine the temperature of the gas discharging from the bed versus the flow rate and versus time. These data would, in turn, be used to determine the mixing ratio between the hot gas coming from the hot bed and the cold gas bypassing the bed.

\subsubsection{Modeling the Packed Bed Heat Exchanger}

When the packed bed was selected as the heat exchanger for the helium, it was decided that a numerical model of the bed heat exchanger should be deroloped. The purpose of the model was two fold. First, it was to be used to determine the heat transfer coefficients using the experimental data; the coefficients could then be correlated as a function of various parameters in the bed. Second, once there was a correlation, the model could predict design criteria for the full scale packed bed.

\subsubsection{The Mathematical Mode1}

To describe the heat transfer process in a packed bet requires two equations;

$$
\frac{\partial T_{b}}{\partial t}=\frac{h a}{M_{b} C_{b}}\left(T_{g}-T_{b}\right),
$$

and 


$$
\rho C_{v}\left(\frac{\partial T}{\partial t}+v_{x} \frac{\partial T}{\partial x}\right)=h a\left(T_{b}-T_{g}\right)-P \frac{\partial v_{x}}{\partial x} \text {, }
$$

with the following boundary conditions: at $t=0, T_{g}=T_{b}=$ known func"ion of $x$ and at $\mathrm{x}=0, \mathrm{~T}_{\mathrm{g}}$ is a known function of time. Equation (1) is the energy equation for the solid of the bed and equation (2) is for the gas. These equations are based on the Eollowing assumptions:

1. The heat transfer between the sol:d and the gas can be described us ing an overall heat transfer coefficient and the difference in local temperature.

2. The walls of the bed are well insulated and there is no radial ccmponent of the heat flux.

3. The thermal conductivity between the, spheres in the bed is negligible and the temperature gradient within each sphere is negligible.

If we also assume that the superficial mass velocity $G$ (i.e. $p v_{x}$ ) is independent of position and helium obeys the ideal gas laws, equation (2) can bo rewritten as

$$
\frac{\partial T_{g}}{\partial t}+\frac{G}{\rho} \frac{\partial \partial T_{g}}{\partial x}=\frac{h x}{\rho C_{v}}\left(T_{b}-T_{g}\right)+\frac{G}{\rho^{2} C_{v}} \frac{\partial P}{\partial x} .
$$

Equation (2) can be further simplified if the bed pressure drop is neglected and the heat content of the gas is small relative to the heat content of the bed ( $\dot{l}_{. e} . \rho C_{v}<<\mathrm{MC}_{\mathrm{b}}$ ); this breaks down at temperatures below 5 where the heat capacity of the bed is very small. Then equation (2) becomes

$$
\frac{\partial T_{g}}{\partial x}=\frac{h a}{G C_{p}}\left(T_{b}-T_{g}\right)
$$

Both equations (3) and (4) were used with equation (1) and gave comparable results, therefore, for most of the work the simpler equation (4) ras used. Equations (1) and (4) are nonlinear because $h, C_{b}$ and $G$ were functions of time and/or temperature. To solve these equations the central difference algorithm described by Wilimott [4] was used. Nonlinear effects were treater by iteration; temperatures calculated by the previous iteration were used to evaluate the nonlinear terms for the nesi iteration. This procedure was repeated until two iterations gave the same temperature. Convergence was rapid since four or less $i^{\wedge}$ :erations were required.

\subsubsection{Determination of Heat Transfer Coefficients}

The experiments were run using the small scale packed bed heat exchanger. The early runs were made at constant flow and with small temperature differences (50 - $100 \mathrm{~K})$ near ambient conditions. Under these conditions the physical properties of the gas are nearly constant; this in turn implies a constant heat transfer coefificient. However, the temperatrie dependence of the heat capac.ty of the bed had to be considered.

* Nomenclature is in section $4.4 \cdot 1.3$ 
Data obtained from the experiments included bed temperature profiles along with flow rates, inlet and exit gas temperatures and pressure drops all as a function of time. To obtain the heat transfer coefficients from these data a trial and error procedure had to be used which compared experimental and calculated time-temperature profiles; it is basically the procedure described by Handley and Heggs [5]. The "correct" value of the heat transfer was the value which gave the best match of the time interval between two arbitrarily chosen temperatures. These temperatures were chosen in the region where the temperature "front" was leaving the bed, $i . e$. where the exit temperature was changing rapidly.

Later runs were made with constant flow and temperature differences as large as $900 \mathrm{~K}$. Under these conditions the physical properties of the gas and solid are both changing as the bed and gas temperature change; thus, the heat transfer coefficient changes. Heat transfer coefficients from the low temperature difference run were adjusted as a function of temperature for these runs. Again the comparison between experimental and calculated time-temperature profiles were made in the region where the tempezature "front" was leaving the bed. Some adjustments to the heat transfer coefficients were made to get the best correlation and the best fit was considered to be the "correct" heat transfer coefficient.

\subsubsection{Nomenclature}

$a=$ heat transfer surface area per unit volume, $\mathrm{m}^{2} / \mathrm{m}^{3}(=\mathrm{G}(1-\mathrm{p}) / \mathrm{d}$ for spheres $)$;

$\mathrm{C}_{\mathrm{b}}=$ specific heat capacity of solid, $\mathrm{J} /(\mathrm{kg} \cdot \mathrm{K})$;

$\mathrm{C}_{\mathrm{P}}, \mathrm{C}_{\mathrm{V}}=$ specific heat capacity of gas, $\mathrm{J} /(\mathrm{kg} \cdot \mathrm{K})$;

$\mathrm{d}=$ diameter of spheres, $\mathrm{m}$;

$\mathrm{G} \quad=$ superficial mass velocity, $\mathrm{kg} /\left(\mathrm{s} \cdot \mathrm{m}^{2}\right)$;

$\mathrm{h}=$ heat transfer coefficient, $\mathrm{J} /\left(\mathrm{m}^{2} \cdot \mathrm{s} \cdot \mathrm{K}\right)$;

$\mathrm{M}_{\mathrm{b}}=$ mass of the bed, $\mathrm{kg}$;

$\mathrm{p} \quad=$ void fraction;

$\mathrm{P} \quad=$ pressure, bar;

$\mathrm{t}=\mathrm{time}, \min$

$\mathrm{T}_{\mathrm{g}}, \mathrm{T}_{\mathrm{b}}=$ temperature of gas and solid respectively, $\mathrm{K}$;

$\mathrm{v}_{\mathrm{x}}=$ linear velocity, $\mathrm{m} / \mathrm{s}$;

$\mathrm{x}=$ axial distance from the front of the bed, $\mathrm{m}$;

$\alpha=$ heat capacity ratio, $\mathrm{C}_{\mathrm{P}} / \mathrm{C}_{\mathrm{v}}$

$\rho=$ density of gas, $\mathrm{kg} / \mathrm{m}^{3}$.

\subsubsection{Test Program for the Sma11 Scale Heat Exchanger}

The dimensions of the heat exchanger bed were to be determined by the analytical model. Since the model was to be adjusted by data from tests of the small scale bed, dimensicns for this bed had to be calculated using estimates. To get the small scale bed dimensions, the bed diameter was arbitrarily selected as $7.6 \mathrm{~cm}$ and the heat transfer coefficient was estimated. The model was then used to calculate the bed length, which was $39 \mathrm{~cm}$. The first small scale bed contained $3.35 \mathrm{~kg}$ of $3 / 8$-inch high-density aluminum oxide spheres. The spheres, which were actually $7.6 \mathrm{~mm}$ diameter, are shown in figure 6 . The hot bed was incorporated into a system which is shown schematically in figure 7 . With this system the bed could be heated by gas flowing through the external electric heater and the bed, or it could be heated by using the internal electric heater. During the tests the inlet gas temperature could be controlled between $80 \mathrm{~K}$ and $350 \mathrm{~K}$ by adjusting the control valves controlling the hot and cold gas flow. 


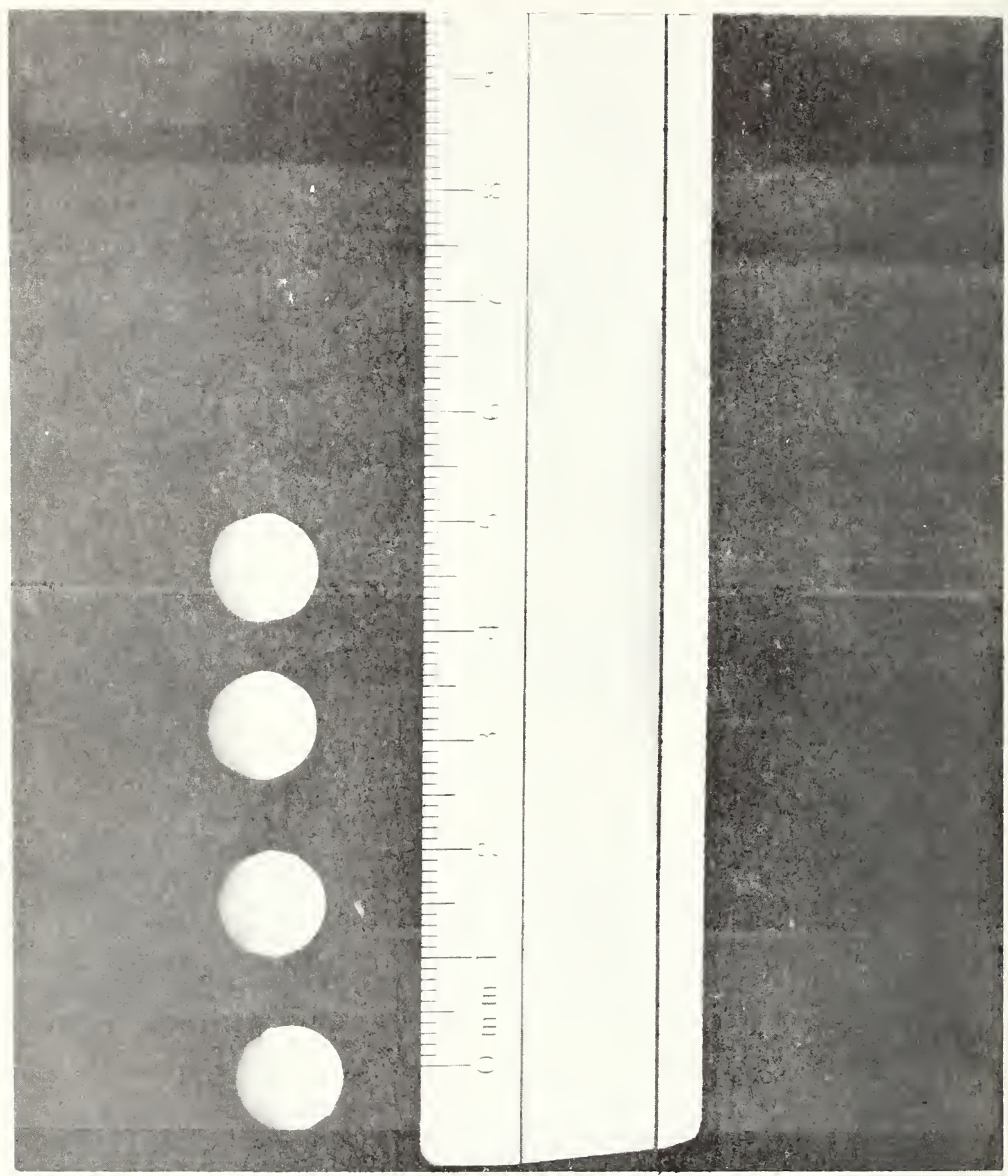

Figure 6. Aluminum oxide spheres used for the hot bed media. 


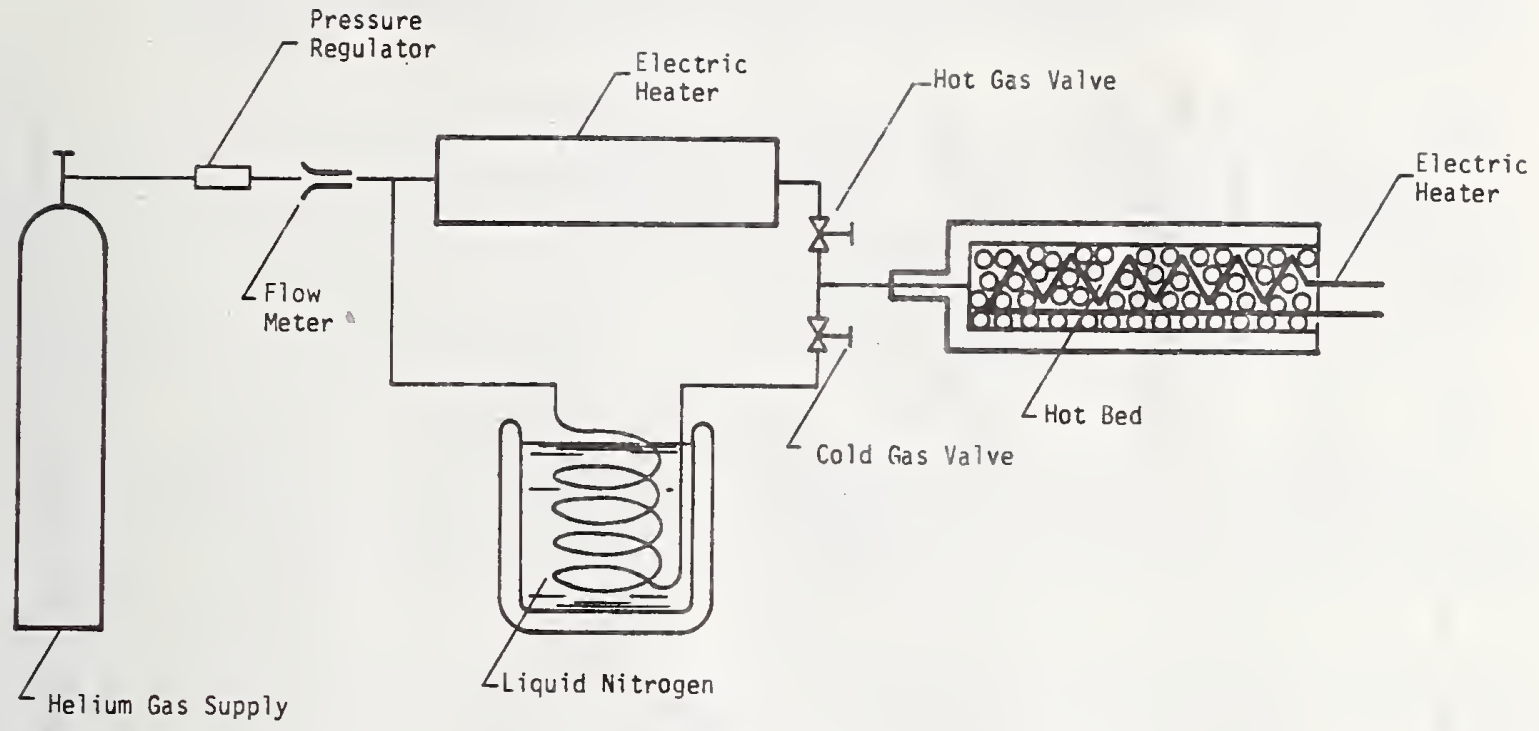

Figure 7. Schematic of reduced scale hot bed test apparatus.

The first time the small scale test bed was constructed, $7.6 \mathrm{~mm}$ diameter spheres were used. Fourteen tests were run on this configuration. Data from these tests indicated that a smaller media might suit the application better by increasing the heat transfer between the bed and the helium. The second bed was built using $1.8 \mathrm{~mm}$ diameter aluminum oxide spheres. Ten tests were conducted with this configuration of the bed. Test results showed that channeled flow was occurring in the bed and the heat transfer was incomplete and unpredictable. Also, the pressure drop in this bed was much higher than in the bed of $7.6 \mathrm{~mm}$ diameter spheres. The decision was to abandon the small media and use the $7.6 \mathrm{~mm}$ diameter spheres.

The bed was rebuilt using the 7.6 diameter spheres and sixteen more tests were made. Test data and the analytical model appeared to correlate in some of these tests. In other tests correlation was poor. Figure 8 shows an example of one of the better correlations.

The calculated value for the heat lost from the hot bed and the heat gained by the helium did not agree in all of the tests. The reason for the discrepancy in the heat balance was discovered when the bed design was examined and it was concluded that the metal end plates, the electric heater and the metal walls of the bed contained heat equivalent to 20 percent of the bed capacity and they were participating significantly in the heat transfer. Since these parts were not instrumented for temperature measurement, their effect had to be estimated and a reasonable heat balance was calculated. Good heat transfer correlation between the test data and the model was not possible though, as the heat transfer coefficient at the walls and end plates was not known and it was not the same as in the bed.

Enough data were taken to determine the effects of bed temperature, inlet gas temperature, and flow rate on heat transfer in the bed. Using these data and the analytical model, the size for the full scale hot bed was predicted. The final bed was then oversized 20 percent to hedge against the unknown effects of the scale up and of the metal parts. The final bed size selected was $34.8 \mathrm{~cm}$ diameter by $40.6 \mathrm{~cm}$ long and the bed contained $74 \mathrm{~kg}$ of 7.6 mm diameter aluminum oxide spheres. 


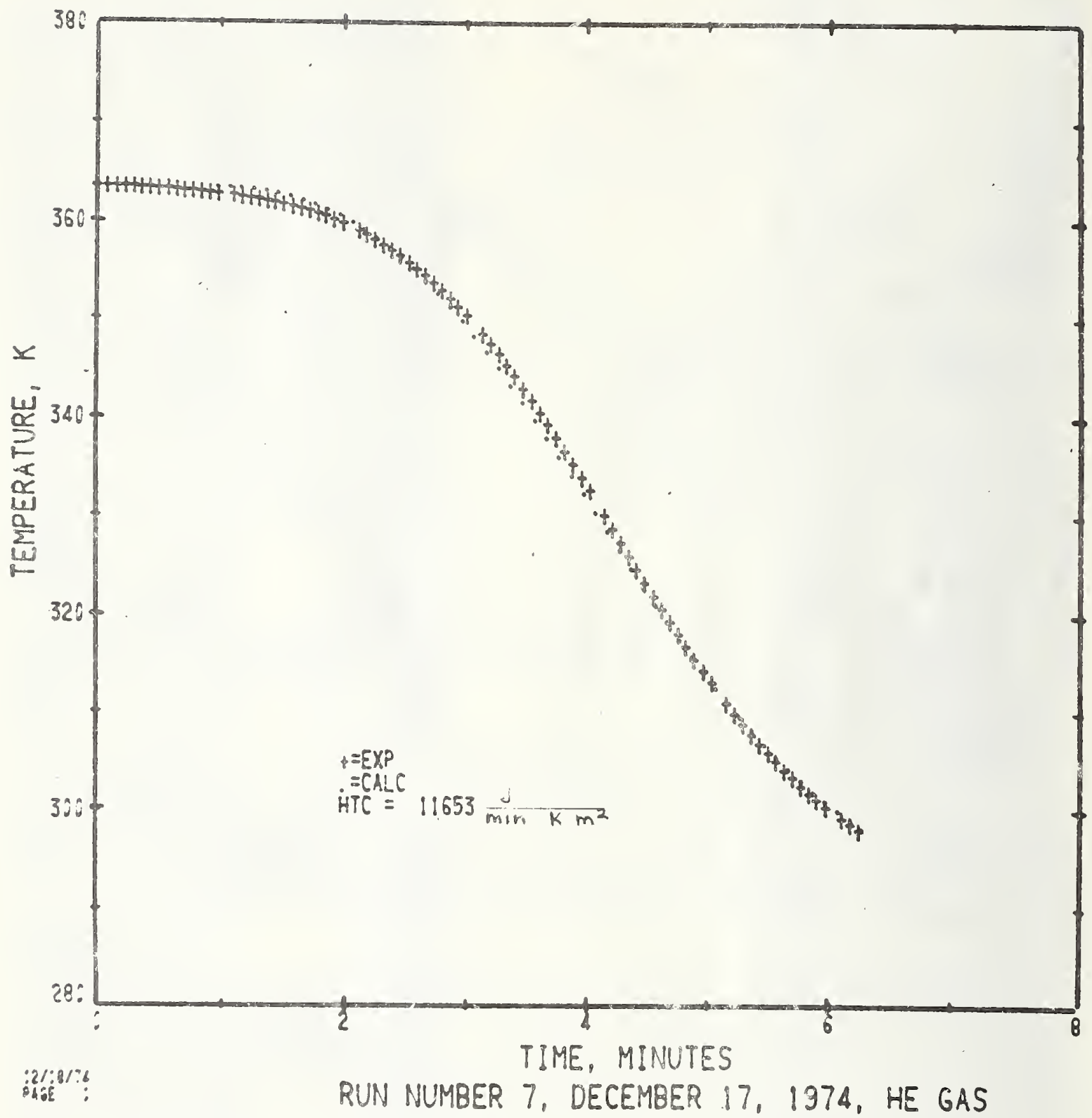

Figure 8. Eed discharge temperature vs. time, predicted and test data.

\subsection{DESIGN OF THE FULL SCALE SYSTEM}

The design parameters for pressure transfer of the liquid helium and for the hot bed heat exchanger were established from the analytical models and the scaled down tests. The designs to be determined by full scale testing were those for the control system and the mixer of the hot and cold gas. Also to be determined from the full scale tests were the effectiveness of the bed insulation and of the electric heater for heating the bed.

At this time in the program the decision was made to use a comercial liquid helium dewar for the balloon filling demonstration. This decision was economic and timely since a special built dewar would cost over $\$ 15,000$ and could not be delivered until well after the scheduled balloon filling date. Also, the desired dewar size could be influenced by the results of the test program and the balloon filling. 
The system, as first constructed, consisted of a pressurant gas cylinder with a valve and a pressure regulator, the liquid helium dewar, the liquid transfer system with flow control nozzles, orifices and valves, the hot bed and the gas mixer. A schematic of a similar system is shown in figure 5 .

To keep the control system as simple as possible, the selected method for fluid control used an electric timer set to control electric solenoid operated valves. Solenoid valves that are either open or closed were selected over modulating valves because they are more reliable at liquid helium temperatures; also modulating valves require more complex controls. The valves and the clock were powered by a 24 volt battery.

The pressurant gas cylinder was a fiber glass and epoxy reinforced aluminum vessel. It weighed $12.2 \mathrm{~kg}$ with a volume of $0.0108 \mathrm{~m}^{3}$. At $31 \mathrm{MPa}$ (4500 psi) it holds equivalent to $3.3 \mathrm{~m}^{3}$ of gas at standard pressure and temperature.

The liquid transfer system originally had two. liquid valves and flow control nozzles. One nozzle was sized to flow half the volume of the other to meet the start requirement of reduced flow. Because of the natural flow restriction occurring during the cooldown of the system, the flow rate in the large flow loop was reduced to the rate required for the first 20 to 30 seconds; the smail flow loop was therefore not needed and it was abandoned after the first two tests.

The liquid helium transfer line was vacuum insulated between the bottom of the helium dewar and the flow control nozzle. The transfer line was not insulated from the valve to the hot bed unit, thereby, the heat transfer with the ambient air was used to convert the liquid helium to 100 percent vapor before it reached two flow control orifices. With 100 percent vapor at the inlet to the orifices, the flow was more predictable than it would have been had it been two phase. These replaceable orifices were used to control the split in the flow between the hot bed and the cold gas bypass. Therefore, these orifices were sized to control the temperature of the gas supplied to the balloon.

The hot bed was packed with $74 \mathrm{~kg}$ of $7.6 \mathrm{~mm}$ diameter aluminum oxide spheres as previously stated. The hot bed was contained in a stainless steel shell which was wrapped with an insulating blanket. The shell and the shell with the blanket installed are shown in figures 9 and 10. This assembly was enclosed in an outer aluminum container which was vacuum tight. The space between the inner and outer vessel was filled with a powder developed for high temperature insulation. The inner vessel was $35 \mathrm{~cm}$ in diameter and the inside diameter of the outer vessel was $45 \mathrm{~cm}$ in diameter. The fiber blanket was $6.35 \mathrm{~mm}$ thick and the powder

was $43.65 \mathrm{~mm}$ thick. The specified thermal conductivity of the blanket was $7.3 \times 10^{-4} \mathrm{~W} /(\mathrm{cm} \cdot \mathrm{K})$. Thermal conductivity for the powder insulation in one atmosphere pressure air was predicted to be $4.04 \times 10^{-4} \mathrm{~W} /(\mathrm{cm} \cdot \mathrm{K})$ with improvement expected in a good vacuum. The insulation space did not contain a good vacuum as considerable pumping time was required to get a vacuum and the pumping rate had to be extremely slow to prevent carrying the powder out with the gas. The final pressure in the insulation was believed to be as high as one half atmosphere because the time available for pumping was limited.

The $2.86 \mathrm{~cm}$ diameter inlet tube was located at the top of the bed and the $12.7 \mathrm{~cm}$ diameter outlet was at the bottom. This orientation was selected to take advantage of thermal stratification in the residual gas in the bed and thus reduce convective heat transfer in the relatively large discharge tube. Since the discharge tube was large, insulation was still needed to reduce heat loss by conduction and radiation during the bed heating cycle. An insulating plug $10 \mathrm{~cm}$ long that was made from the same material as the insulation blanket was used for the test program. This plug was manually removed before each test. Systems for automatic removal of the insulation plug are discussed in section 9.

The hot bed was heated using an electric heater that had $640 \mathrm{~cm}$ of heated length and was $1.21 \mathrm{~cm}$ in diameter. This heater drew 7.5 amperes at 220 volts ac. It was coiled $30.5 \mathrm{~cm}$ in diameter for 6-1/2 turns with the turns spaced closer at the ends of the bed. This closer spacing at the ends was used to counteract the high heat losses through the inlet and outlet tubes. An automatic control was used to control the heater temperature. The maximum operating temperature of the heater and the control unit was $1090 \mathrm{~K}$.

Four shielded thermocouples were equally spaced axially through the bed for measuring bed temperature. One thermocouple was strapped to the heating element to be used as the temperature sensor for the heater control. 


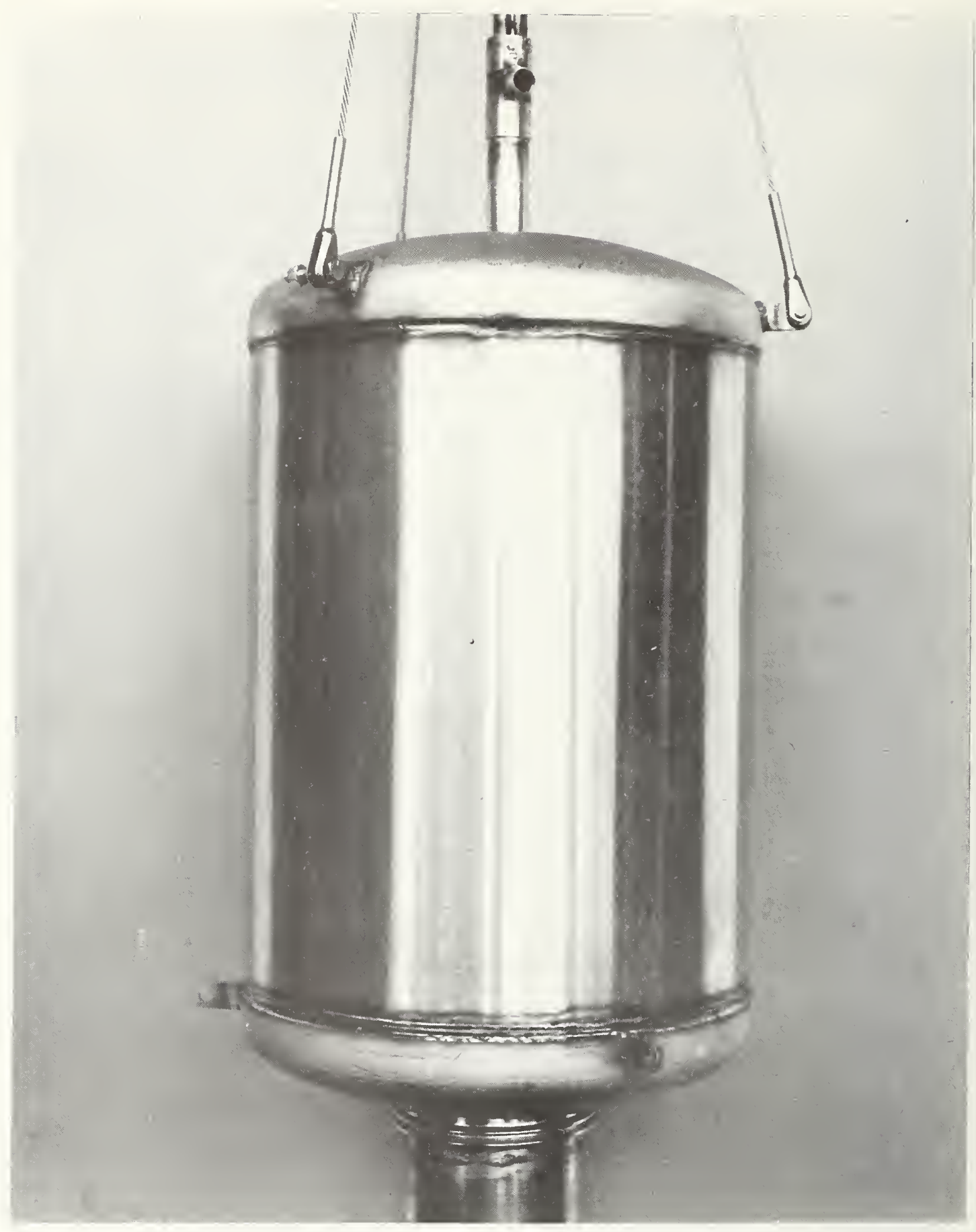

Figure 9. Hot bed inner vessel. 


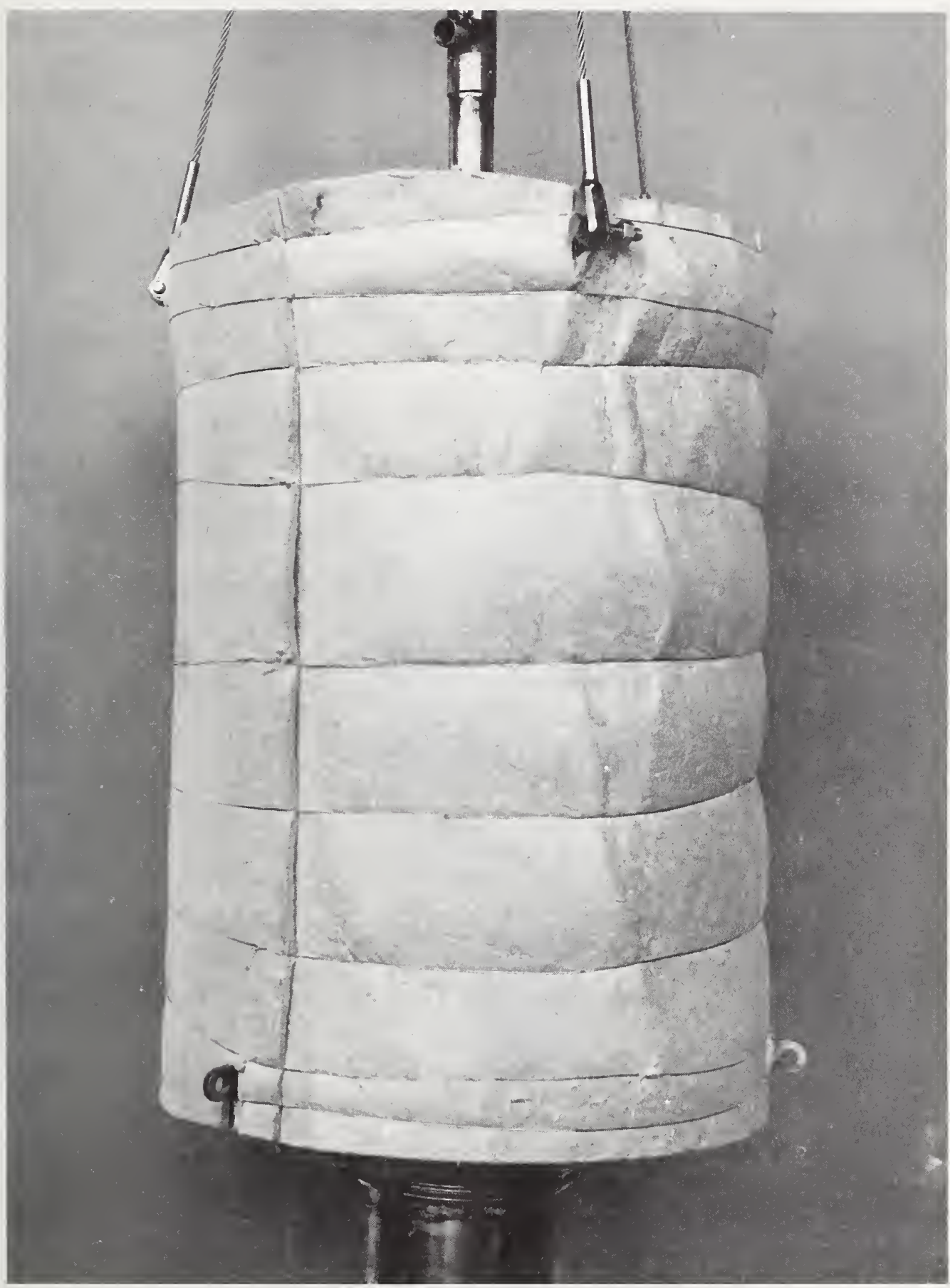

Figure 10. Hot bed inner vessel with the insulation blanket. 
A small gas deflector and some brass sponges were placed in the inlet end of the hot bed to help spread the inlet gas flow evenly across the bed. A cross section of the hot bed is shown in figure 11.

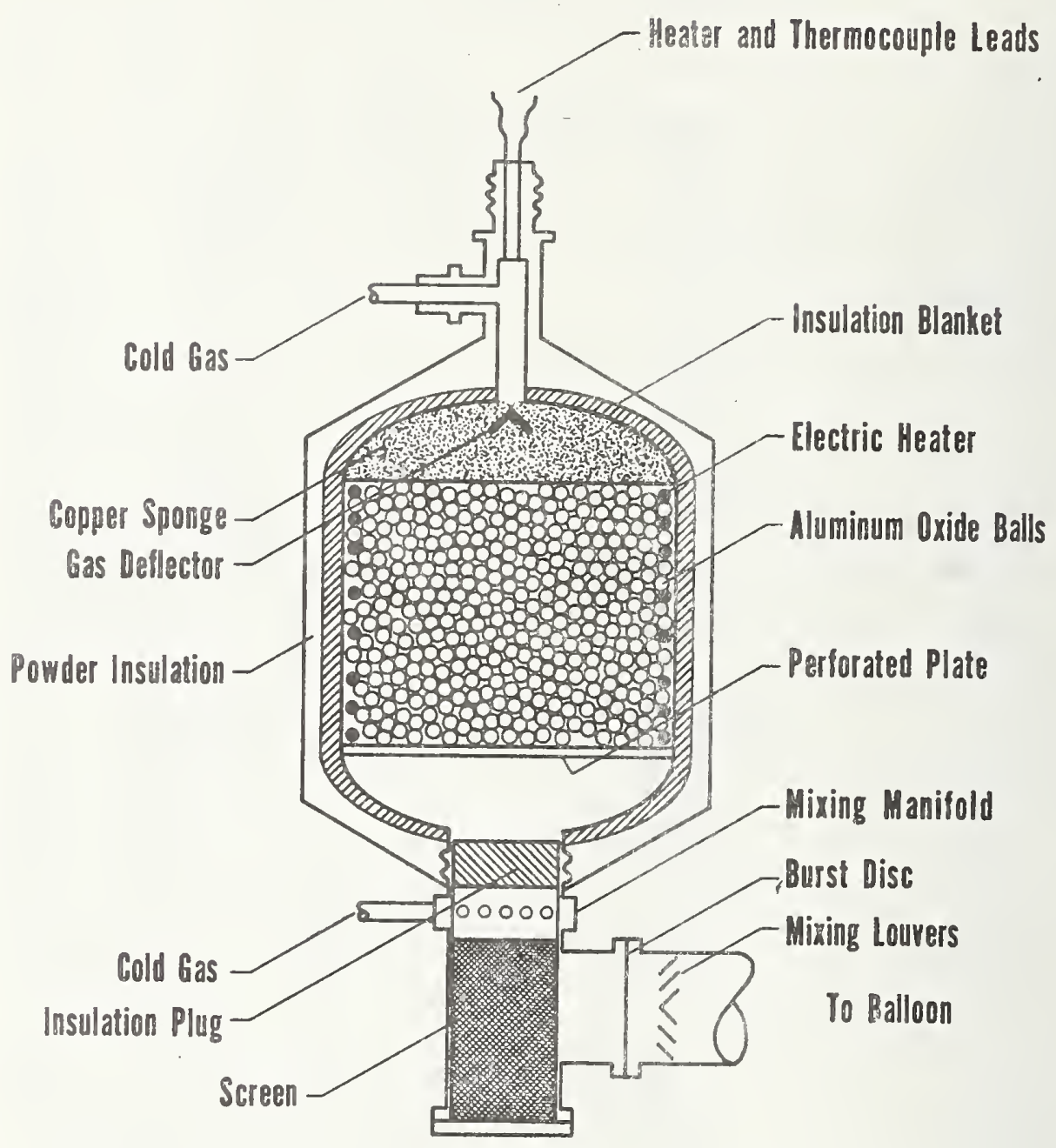

Figure 11. Cross section of the heat exchanger assembly.

\subsection{INSTRUMENTATION}

Temperatures were measured at the nozzle, at both of the orifice inlets, at the gas discharge tube and at the four points in the hot bed. Five thermocouples were installed in the gas discharge tube. Four were equally spaced at $3.8 \mathrm{~cm}$ radius in the $6.4 \mathrm{~cm}$ radius discharge tube. The fifth was at the center. Carbon resistance-thermometers were used to measure the temperature at the nozzle inlet and at the orifice inlet. Pressures were measured at the ciewar, at the inlet and throat of the nozzle and at the inlet and discharge of the orifices. The pressure taps at the nozzles and the orifices were placed according to ASME recommendation for flow measurements in long radius nozzles and in sharp edge orifices. Flow was calculated from these pressure and temperature measurements. 
Test data were taken automatically using a minicomputer and an automatic data acquisition unit. Figure 12 shows an example of the data printout for data taken at 62 and 95 seconds after the start of a test.

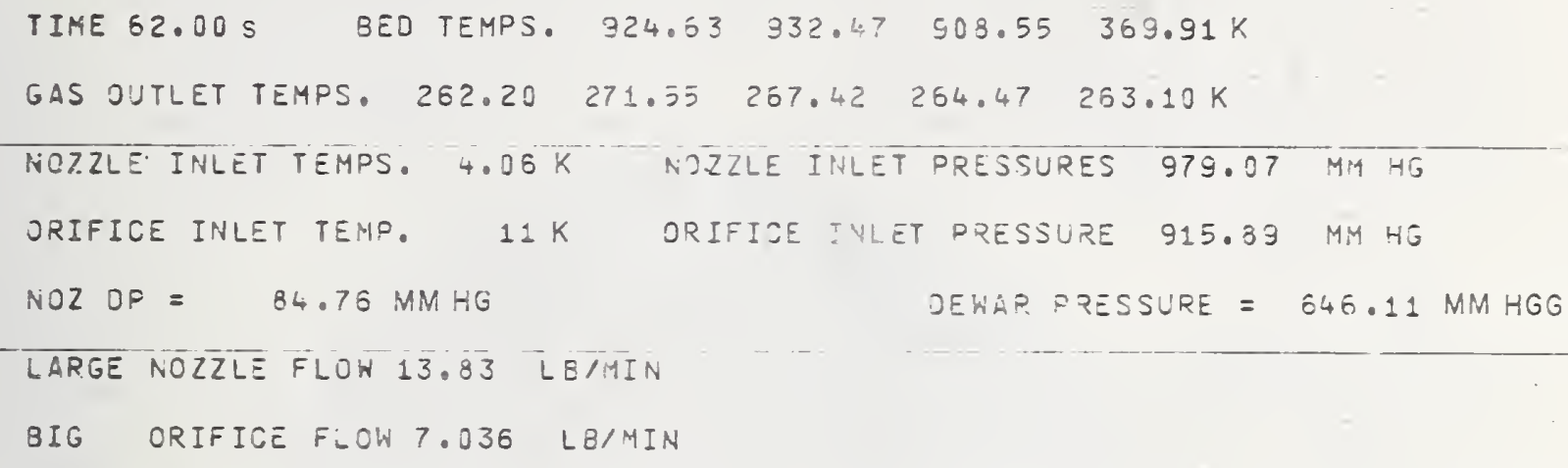

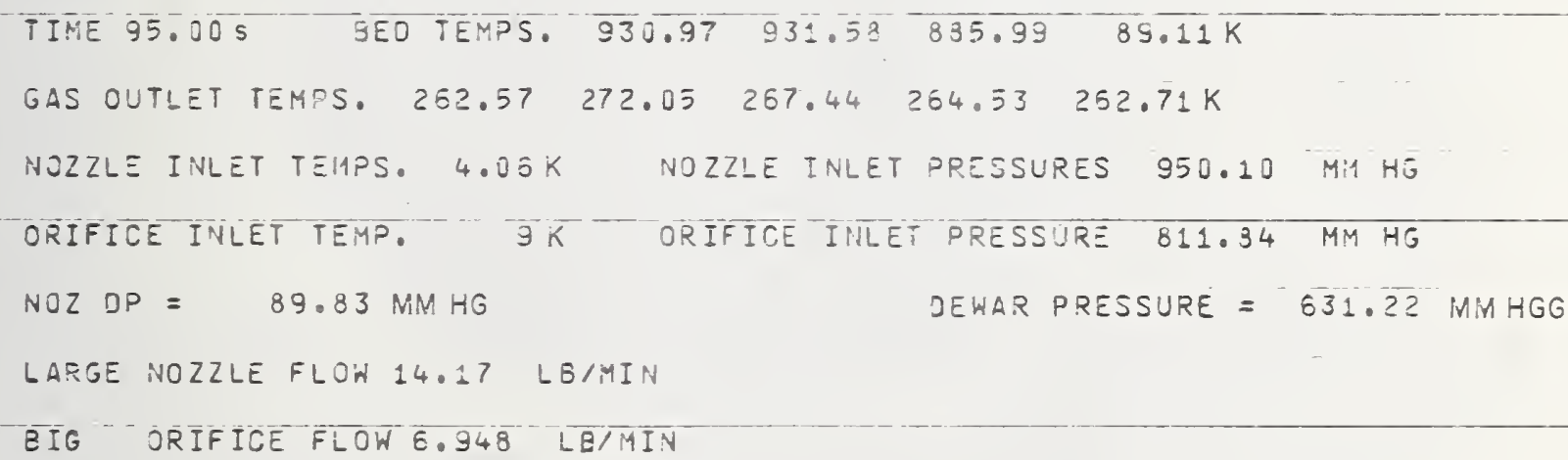

Figure 12. Typical data printout frcm the test program.

\section{FULL SCALE TEST PROGRAM}

The initial phase of the test program was to evaiuate the startup transient and to set the timing of the valves. The remainder of the test program was to develop mixing and to evaluate the effectiveness of the bed for the full duracion of tha run.

\subsection{Startup Transient and Valve Timing Tests}

Fifty liters of liquid heiiun was enough for the startup transient and approximately 20 seconds of relatively steady state flow. Three tests using 50 liters each were required to determine the correct length of the uninsulated line to get temperatures at the orifices slightly above liguid helium tempercture. The orifice inlet cemperature of $9 \mathrm{~K}$ was the final temperature obtained with 1.82 th of non-insulated line. Four nore tests were required to find the right flow ratio between the hot and cold gas. During the four tests a valve was adled to the hot bed inlet to delay the flow of hot gas. This delay was required because the outlet gas temperature was greater than the upper limit for the first 10 seconds after start.

The gas flow rate was low during these first tests so the dewar pressure was increased to ircrease the flow. The last two runs were made with the dewar pressure at the maximum allowable for the comercial dewars - $103 \mathrm{kPa}$ gauge (15 psig) - but the flow rate was still 20 percent below the design flow of $0.16 \mathrm{~kg}$ per second. The flow restriction was in the transfer line between the dewar and the flow control nozzle. Flow could not be increased without considerajle hardware changes in the system and changes in the dewar since the 
transfer line was the largest diameter that the dewar fitting would pass. Instead of making changes to the dewar fittings, the decision was made to proceed with the low flow rate knowing that an increase in the size of the dewar opening and in the liquid helium transfer line would solve the flow problem.

To prolong heater life, $925 \mathrm{~K}$ was selected as the design bed temperature instead of $1090 \mathrm{~K}$ which was the maximum temperature rating for the heater. The heater required 14 hours to heat the bed to $925 \mathrm{~K}$. At $925 \mathrm{~K}$ bed temperature and $300 \mathrm{~K}$ ambient temperature, the outer wall of the hot bed was $375 \mathrm{~K}$ in still air. This was near the estimated temperature for the insulation system with one atmosphere pressure air in the insulating powder. The outer wall temperature should be reduced significantly if a vacuum is maintained in the powder insulation. For the test program the outer wall temperature was reduced to $322 \mathrm{~K}$ by forcing air across the unit at $2.5 \mathrm{~m} / \mathrm{s}$ velocity.

\subsection{Testing of the Packed Bed and the Gas Mixer}

The second phase of testing was to develop the mixer and to control steady state outlet temperatures between the design limits of 218 to $323 \mathrm{~K}$. The second phase testing started with a full length test using 400 liters of liquid helium. During this test the outlet temperature was satisfactory for the first four minutes, then it dropped below the allowable limit of $218 \mathrm{~K}$ for the last 90 seconds. Also, the outlet temperature range was 100 degrees, so gas mixing was inadequate.

To improve the mixing of the hot and cold gas a new manifold mixer was designed to inject equal volumes of the cold gas into three equal areas of the hot gas stream. Also a mixer was added to the discharge tube. This mixer consisted of three half moon discs oriented at $1,0^{\circ}$ and spaced at one half tube diameter apart. Mixing was satisfactory with these mixers but the half moons created a high velocity gas stream in one side of the discharge tube. This higi. velocity jet was damaging to the plastic tube that was to be used to direct the gas from the unit to the balloon.

Another gas mixer was designed for the discharge tube. This mixer used three sets of louvers oriented at $90^{\circ}$ and spaced one half tube diameter apart. The first set of the louvers are shown in place in figure 13. This configuration proved to give good mixing and uniform discharge velocity.

To increase the gas temperature for the last 90 seconds of the run, a higher flow rate was required to the hot bed. The flow to the hot bed had been previously increased by completely removing the flow control orifice during startup transient tests; therefore, the flow delay valve was now restricting the flow. This valve was replaced with a larger valve. Then another 50 liter test was run to evaluate the effects of the larger valve. The larger valve increased the hot gas flow but it caused a high temperature spike at the beginning, so the opening of this valve was delayed an additional four seconds. The increased flow to the hot bed resulted in an increase of $50 \mathrm{~K}$ in the average gas cutlet temperature during steady state conditions.

The increased flow through the hot bed was a potential solution to the 90 second cold flow problem at the end of the run, but, actually the increase in flow created a worse problem because calculations showed that the hot bed did not contain enough energy for an increase in the gas temperature of $50 \mathrm{~K}$ for the full run duration. To eliminate this problem a second cold gas bypass was added to the system to increase the cold gas flow and therefore raduce the average gas outlet temperature. This bypass contained a valve and a flow control orifice. The bypass was opened 30 seconds after startup and was closed when the outlet gas temperature dropped to near the lower limit. One test was required to determine the correct size of orifice so that the discharge gas temperature remained below $260 \mathrm{~K}$ during the steady flow operation. Then, a full length run was nade to determine the time at which the bypass valve was to be closed. During this run the maximum temperature spread at the gas out lot was $28 \mathrm{~K}$, and except during the initial two second high temperature spike, the outlet gas temperature remained between 220 and $313 \mathrm{~K}$. The initial high temperature spike to $355 \mathrm{~K}$ was caused by the hot residual gas in the mixing chamber flowing out ahead of the cold gas entering during the start. Since the duration of the spike was short it was acceptable as the plastic fill tube was not damaged. The addition of the second cold gas bypass did not increase the total flow rate but just redistributed the flow. As mentioned earlier the total flow rate was limited by the transfer line in the dewar.

The system was ready to be demonstrated by filling the balloon. Figure 14 is a schematic of this system. Figure 15 is a picture of the heat exchanger and the control valves. 


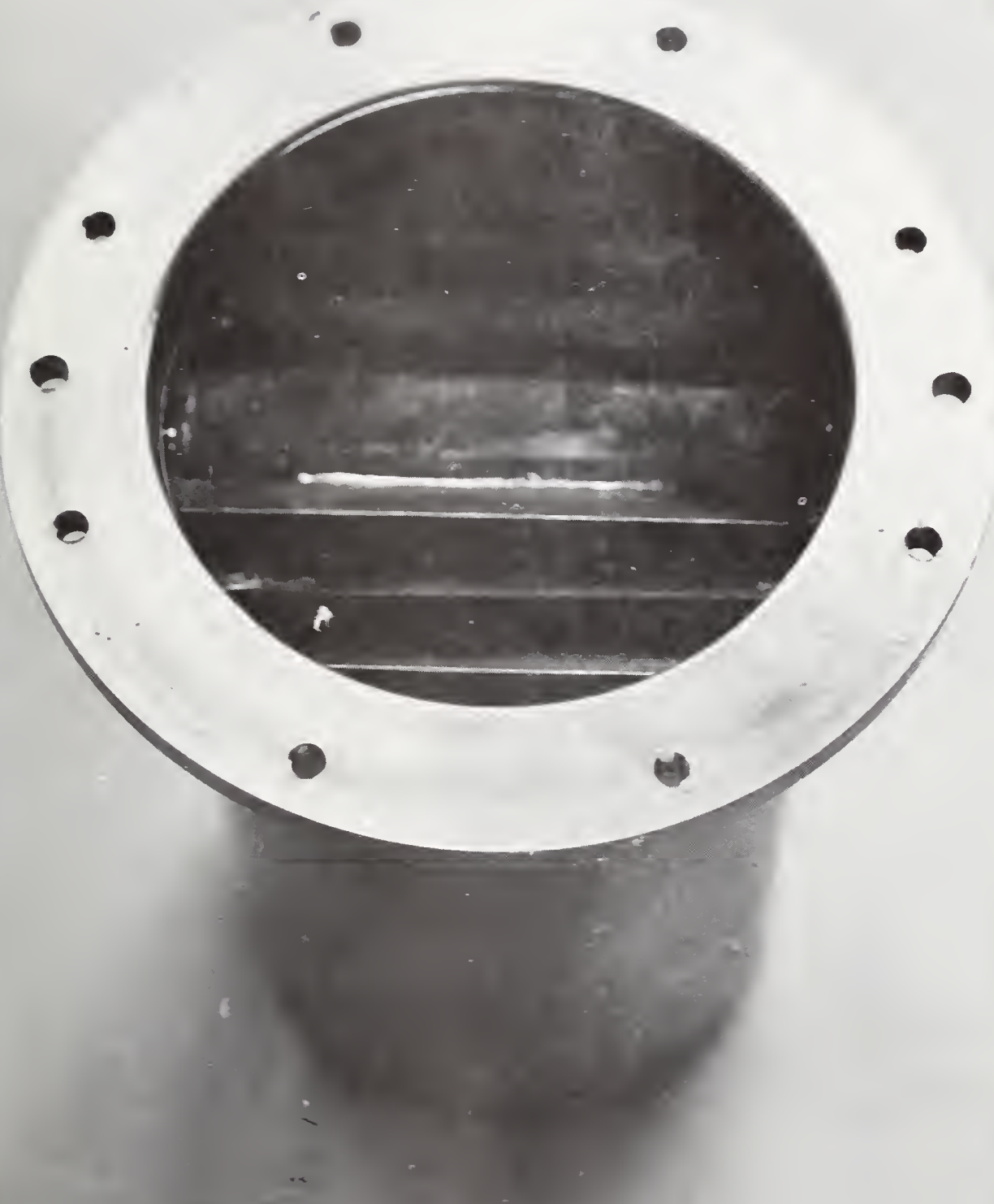

Figure 13. Louvered gas mixer. 


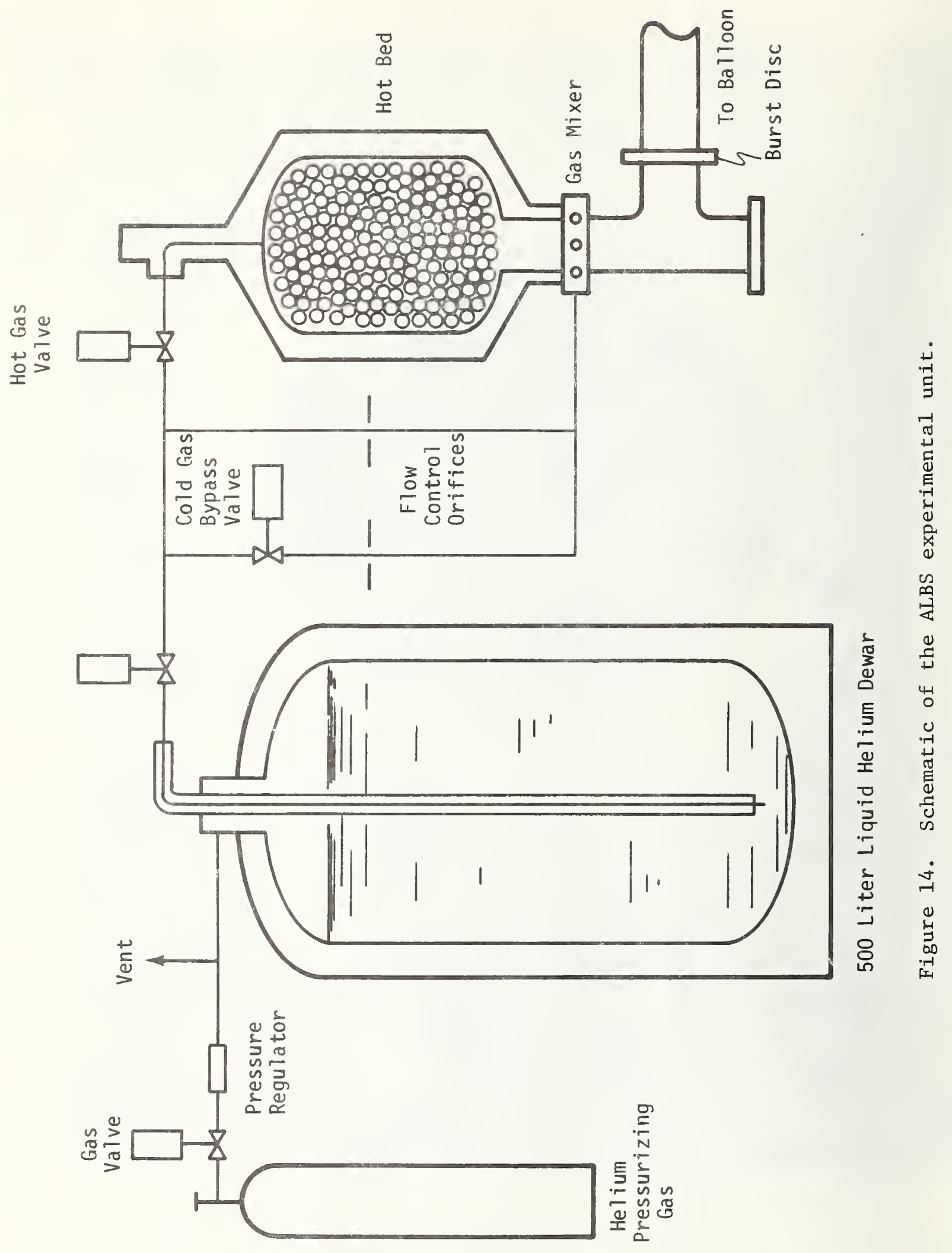




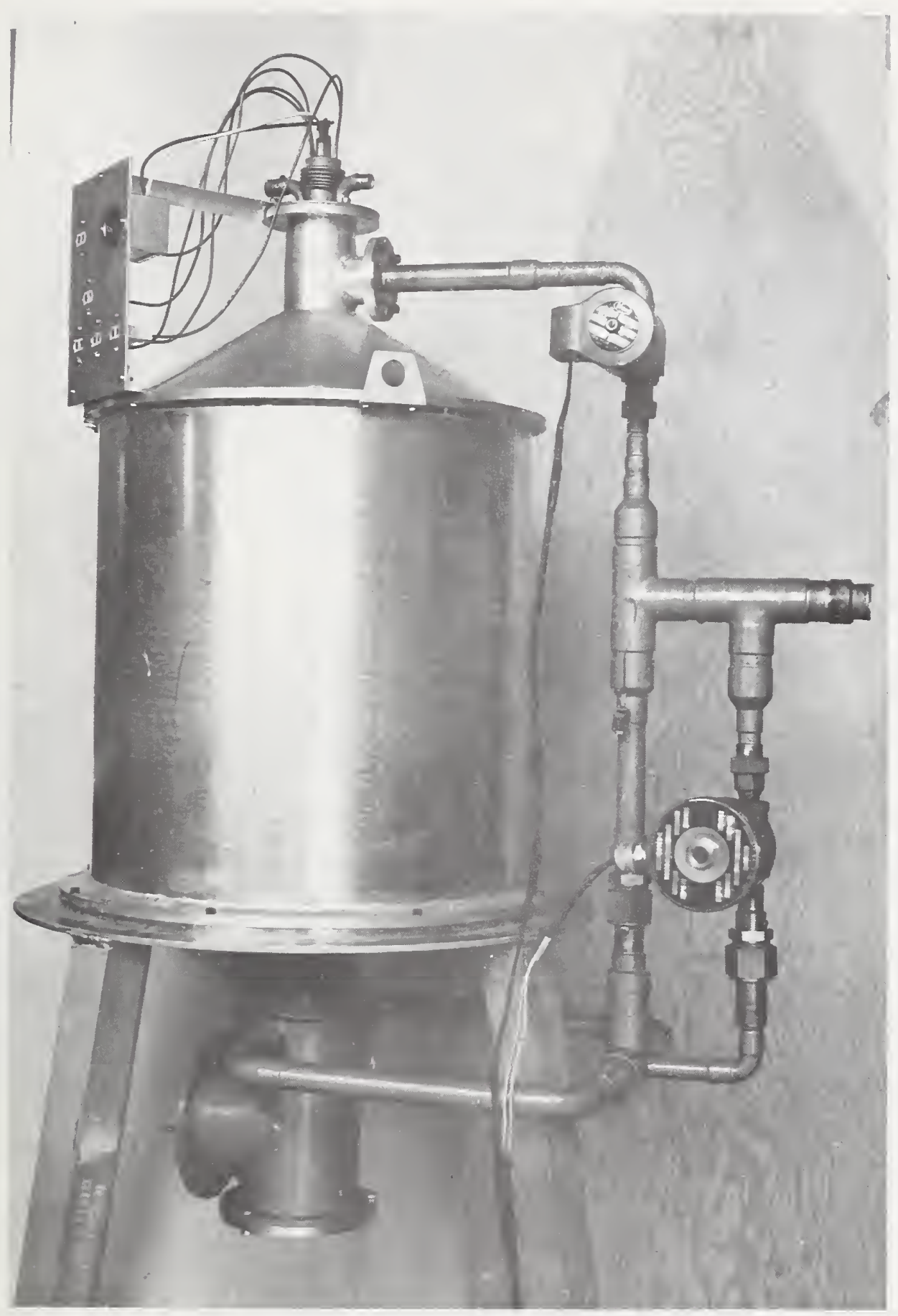

Figure 15. ALBS heat exchanger and plumbing. 
The balloon used for the demonstration was $8.2 \mathrm{~m}$ high and $8.6 \mathrm{~m}$ diameter. The design volume was $287.5 \mathrm{~m}^{3}$; the balloon material was $0.05 \mathrm{~mm}$ thick polyethylene. Both the top and bottom end fittings were aluminum castings. The top fitting contained a large, remotely controlied valve for exhausting the inflating gas. The bottom end fitting contained a tie down bolt and a $12.7 \mathrm{~cm}$ diameter inlet tube for filling the balloon.

The test procedure for filling the balloon was as follows:

1. The hot bed was heated to $925 \mathrm{~K}$.

2. The test was started by opening the main liquid valve.

3. The gas flow to the hot bed was delayed 14 seconds.

4. The second cold gas bypass flow was delayed 30 seconds and was turned off at 4 minutes, 45 seconds.

The run lasted six minutes, 47 seconds and consumed 355 liters of liquid helium. The overall average gas temperature at the unit discharge tube was $265 \mathrm{~K}$ and the barometric pressure was $626 \mathrm{~mm} \mathrm{Hg}(83.5 \mathrm{kPa})$. At this temperature and pressure, 355 liters of liquid weighs 45.8

$\mathrm{kg}$ and produces $311 \mathrm{~m}^{3}$ of gas. Figure 16 is an overall view of the system prior to filling. Figure 17 shows the non-insulated transfer line and the valves during the run. Frost and drops of liquid air are visible on the non-insulated line from the valve to the heat exchanger. Figure 18 shows the balloon immediately after filling.

The filling of the balloon was successful and no unexpected incidents developed. The system ran completely automatic after the start switch on the control clock was manually actuated.

\section{DISCUSSION OF THE EXPERIMENTAL SYSTEM}

The experimental system was a self-contained package that was automatic once the starting switch was actuated. The two elements of the system that were not developed for airborne use were the helium dewar and the insulation plug in the discharge tube of the hot bed. The dewar technology is well developed and a dewar can probably be designed and built that will meet the design criteria of size and weight without a development program.

\subsection{Insulation in the Hot Bed Discharge Tube}

The insulation plug in the discharge tube of the hot bed must be removed automatically in the airborne system and the scheme for removal will require some development. Several schemes that can be explored are presented in figures 19 through 21 . The schemes shown in figures 19 and 20 use powder as the insulator. This may prove to be unreliable depending on the packing and caking characteristics of the powder over a long period of storage. These two schemes would require vertical orientation of the heat exchanger at all times.

The scheme shown in figure 21 requires more space but could probably be made to operate very reliably. The development of the insulation scheme for the discharge tube was excluded from the program at the time the decision was made to perform only ground demonstrations of filling the balloon. This decision was made to conserve overall program time.

\subsection{ALBS System Weight}

The heat transfer unit as built weighed $166 \mathrm{~kg}$, which is about the design objective weight for the entire cryogenic package. However, the hot bed was built using hardware available instead of waiting for specially fabricated parts. Hardware such as the heads for the inner shell of the heat exchanger were much heavier gauge than was required. Valves were selected from industrial stock to expedite delivery and reduce cost. Also, the bed mass was increased twenty percent over the calculated needs. If the bed were resized to the minimum weight and the hardware was built using typical aircraft design instead of industrial design, the estimated weight of the system would be as shown in Table 2 .

The total weight of $224.7 \mathrm{~kg}$ is still 40 percent over the design objective but is not so large as to be unacceptable. It is still as light as the gas generator systems using heat exchangers and the system does not contaminate the inflating gas. It is also much less complicated than most gas generating systems as the only operating parts are the clock and four solenoid valves.

The estimated size of package for the system is a cylinder $91 \mathrm{~cm}$ in diameter by $180 \mathrm{~cm}$ long which is only 8 percent longer than the design objective of $166 \mathrm{~cm}$. 


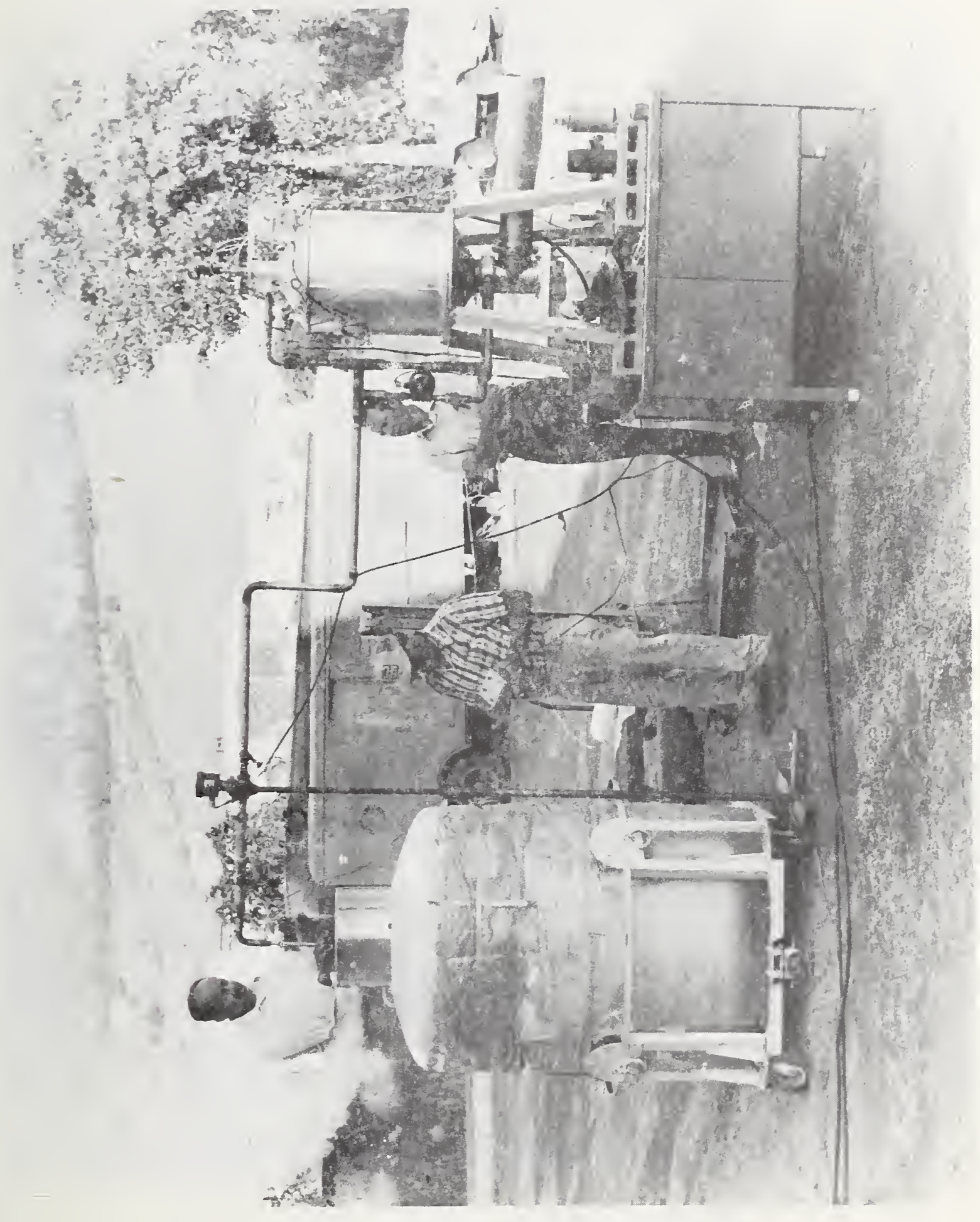

Figure 16. ALBS before the demonstration filling of the balloon. 


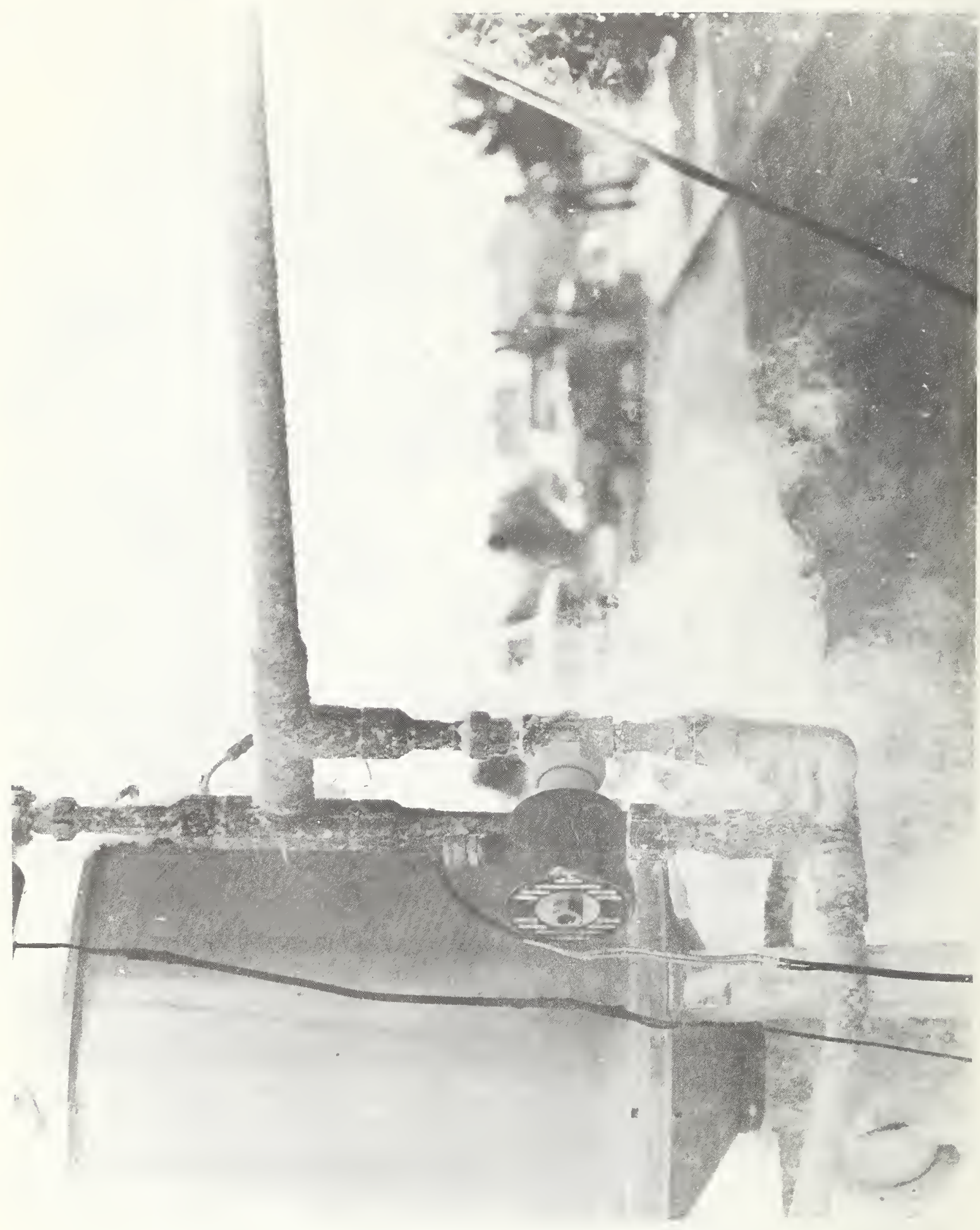

Figure 17. The cold gas plumbing during the filling of the balloon. 

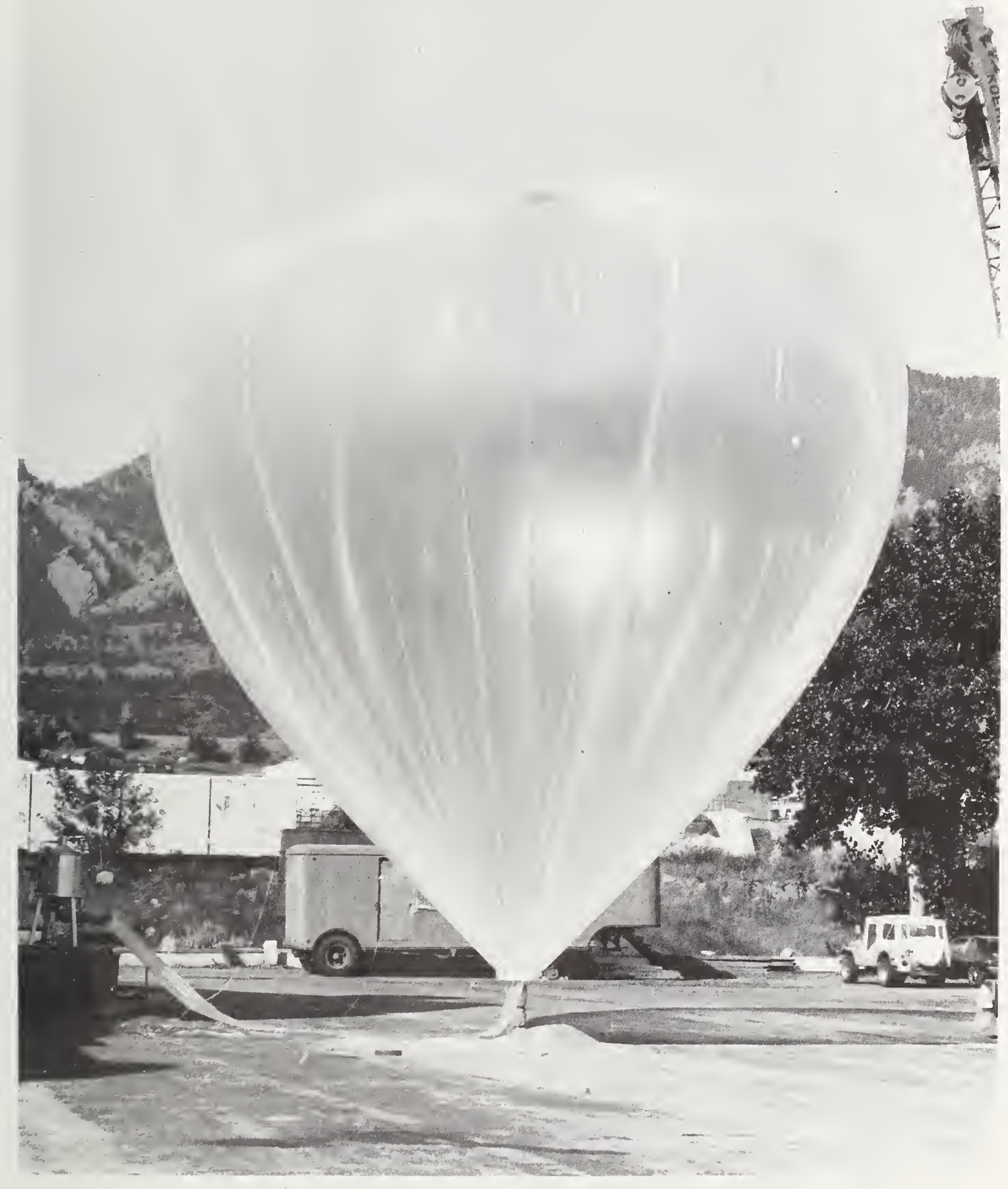

Figure 18. The filled balloon. 


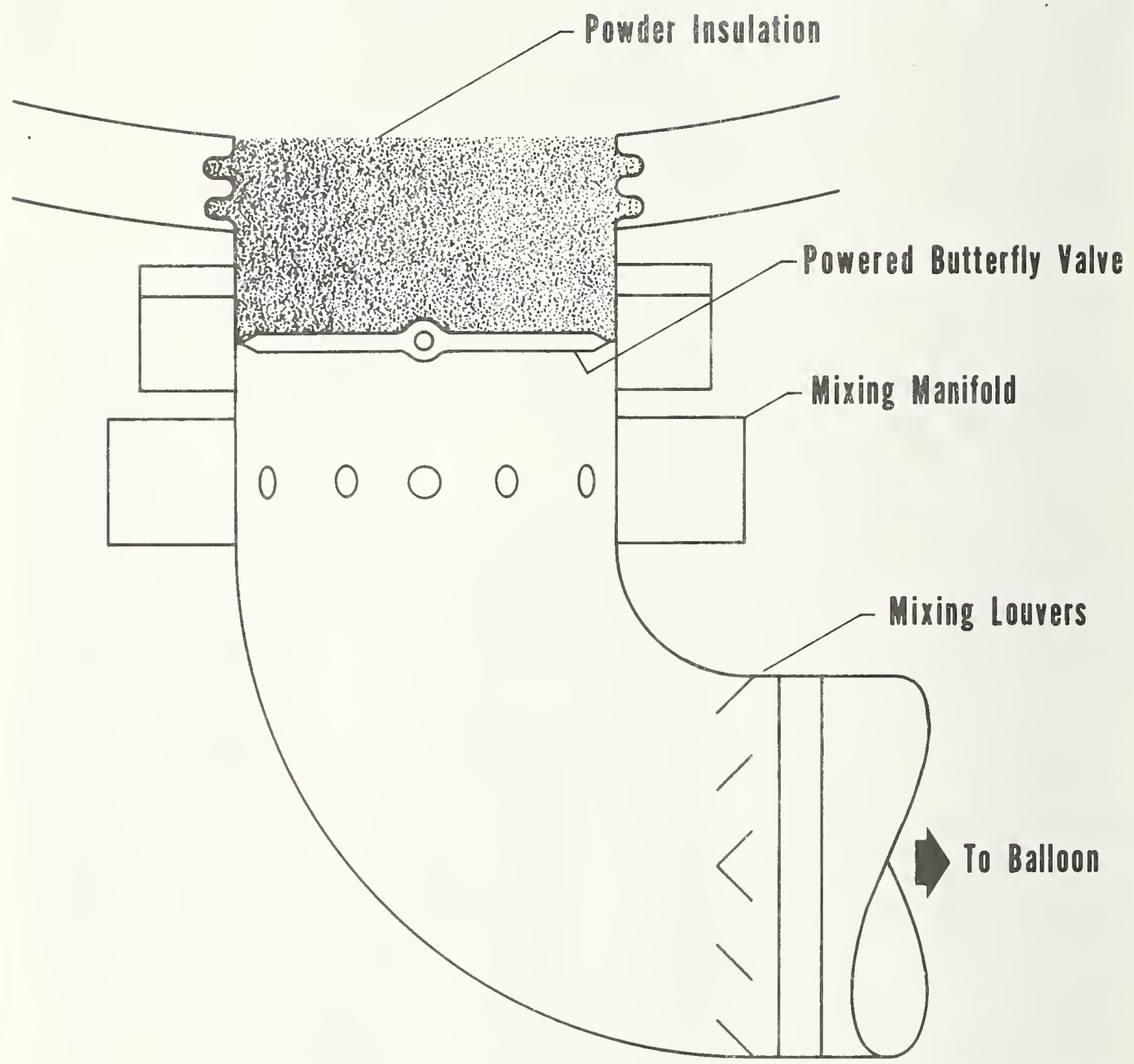

Figure 19. Discharge tube insulation using powder on a butterfly valve. 


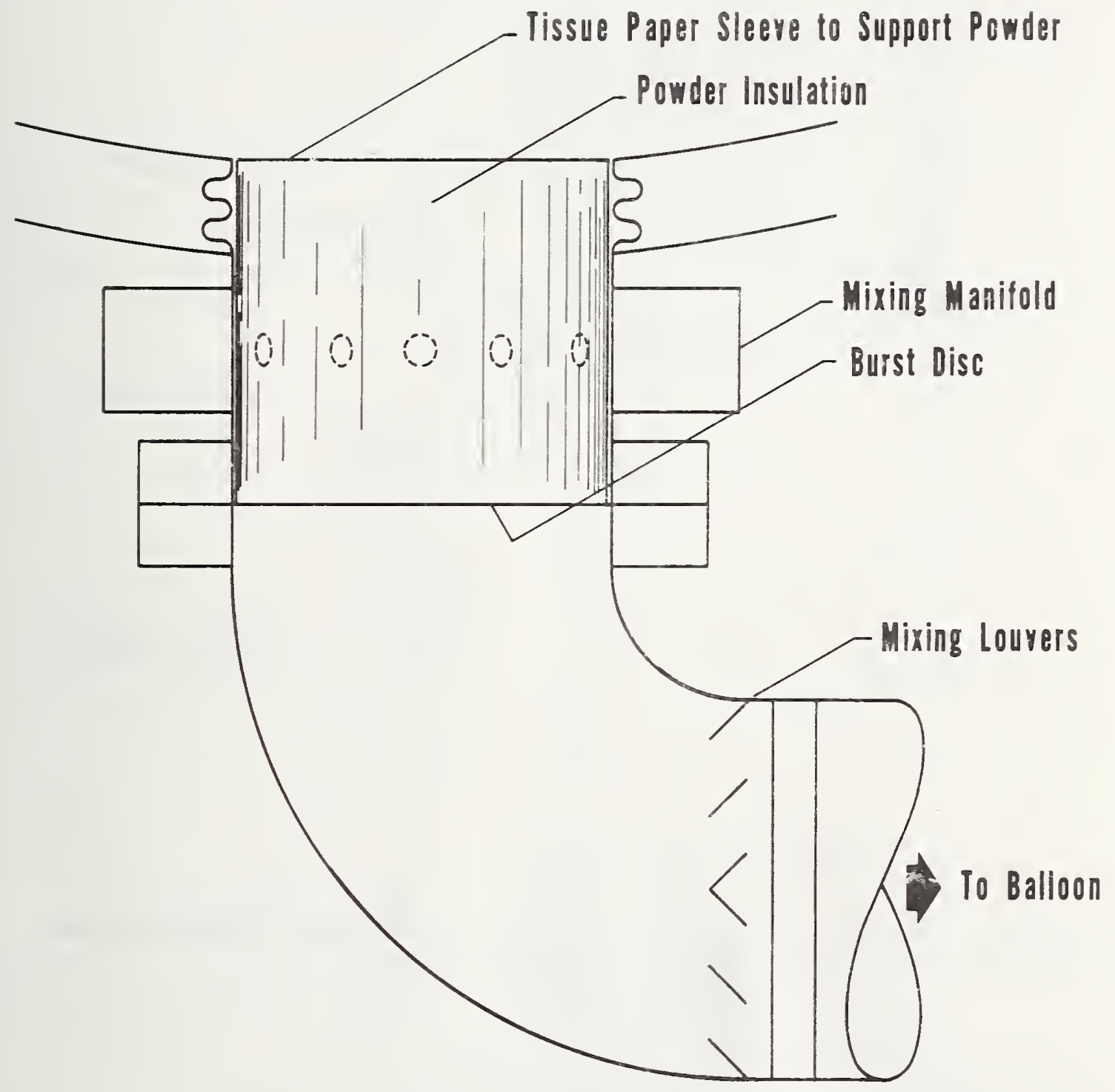

Figure 20. Discharge tube insulation using contained powder on a burst disc. 


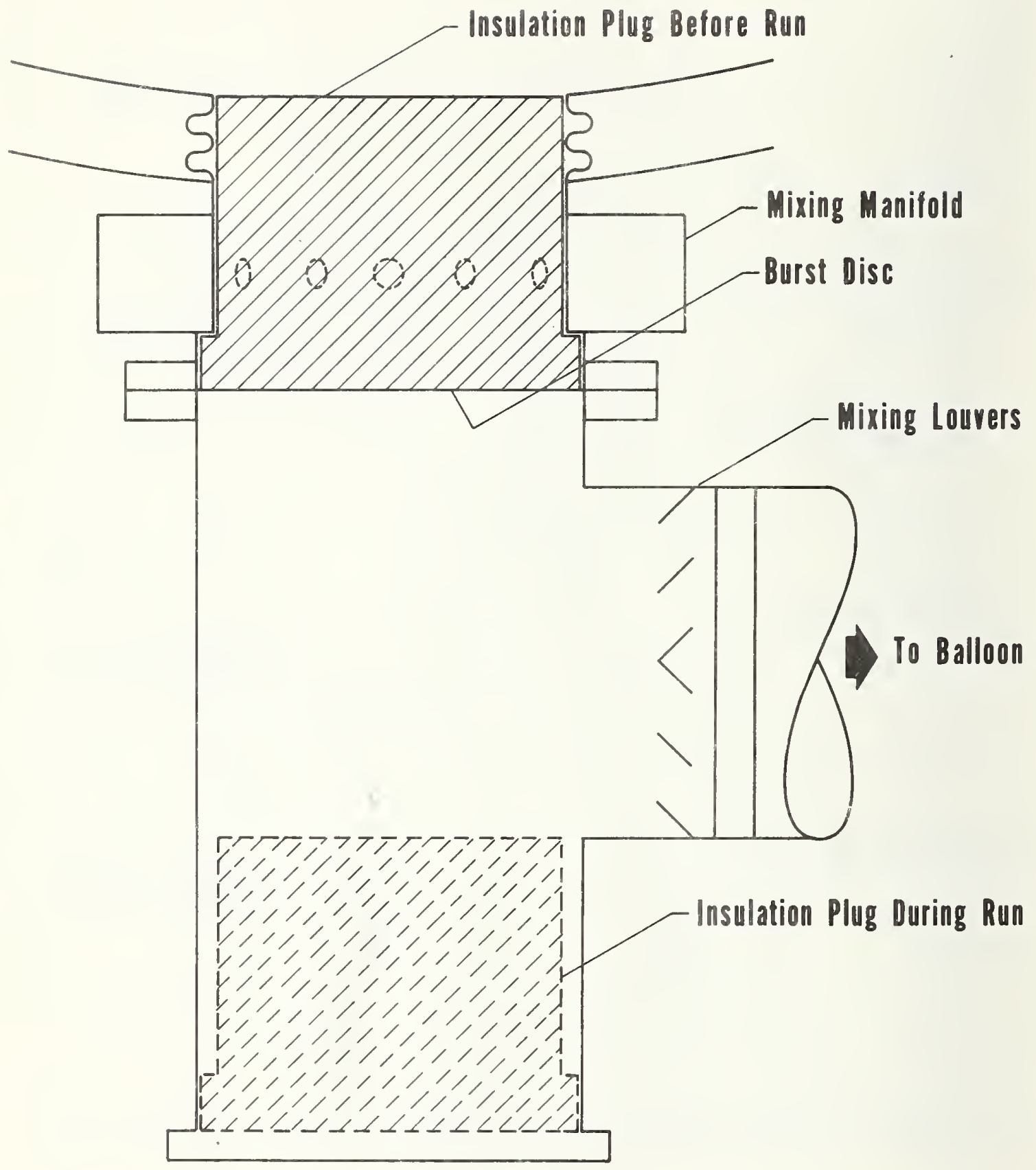

Figure 21. Discharge tube insulation using a moving fiber plug. 
Table 2. ALBS Weights

Component

Estimated Weight

$\mathrm{kg}$

Hot Bed and Plumbing

Bed media

Inner vesse 1

Outer vessel

Valves

Pipe

Mixer

Pressurization System

Gas cylinder

Valve

Regulators

Liquid and Dewar

Dewar

Liquid

Controls

Clock

Batteries

TOTAL

Sub Tota1

Sub Total $\overline{114.5}$

Sub Total
60

12

9.1

7.9

1.0

1.8

91.8

12.2

0.7

1. 6

Sub Total
12.2

Experiment Weight

$\mathrm{kg}$

74

40

22

16

5

$\frac{9}{166}$

. 7

1.6

14.5

applicable not

68.7

45.8

1.6

1.6

2.3

3.9

$\overline{224.7}$

2.3

3.9

\section{CONCLUSIONS}

The demonstration filling of the balloon is believed to be the first successful filling of a large balloon using liquid helium to supply the inflating gas. The filling demonstration occurred without incident and was totally controlled by the electric clock mechanism from the time the clock was started until the balloon was full.

The conclusions from the experiments and demonstration balloon filling are: 1) a balloon can be filled using liquid helium and a hot packed bed to convert the liquid helium to warm gas; 2) the filling of a balloon can be totally automatic and can therefore be accomplished completely remote, while the balloon is suspended from a parachute; and 3) the system is simple, reliable and lightweight.

Some development work is still required on the high temperature insulation scheme used in the hot gas discharge tube and to optimize the packaging of the hot packed bed and the liquid helium. 


\section{REFERENCES}

1. Payne, James C., Final report on the hurricane positioning device feasibility study, Project 7776, Task 67642, Air Force Cambridge Research Laboratories, L. G. Hanscom Fie1d, Bedford, Mass. (1960).

2. Carten, Andrew S., At investigation of techniques for launching large balloon systems from aircraft or rockets in flight, AFCRL-TR-73-0633, Air Force Cambridge Research Laboratories, L. G. Hanscom Field, Bedford, Mass. (1973).

3. Goldsmith, A., Waterman, T. and Hirschborn, H., Handbook of thermal physical properties of solid material, The Macmillan Company, New York, N.Y. (1961).

4. Willmott, A. J., Simulation of a thermal regenerator under conditions of variable mass flow, International Journal of Heat and Mass Transfer, 11, p. 1105 (1968).

5. Handley, D. and Heggs, P. J., Momentum and heat transfer mechanisms in regular shaped packings," Trans. Istn. Chem. Engr., 46, T251 (1968). 


\begin{tabular}{|c|c|c|}
\hline $\begin{array}{l}\text { U.S. DEPT. OF COMM. } \\
\text { BIBLIOGRAPHIC DATA } \\
\text { SHEFT }\end{array}$ & $\begin{array}{l}\text { 1. PLIBLIC ATION OR REIPORT NO. } \\
\text { NBSIR } 76-834\end{array}$ & 3. Recipicent $s$ Accessesen $x$ \\
\hline \multirow{2}{*}{\multicolumn{2}{|c|}{$\begin{array}{l}\text { 4. TITLE AND SUBTITLI: } \\
\text { A SYSTEM FOR INFLATING A BALLOON USING HELIUM STORED IN THE } \\
\text { LIQUID PHASE }\end{array}$}} & $\begin{array}{l}\text { S. Publicarion Dare } \\
\text { January } 1976\end{array}$ \\
\hline & & $\begin{array}{l}\text { 6. Performing Organizarion (, the } \\
275.05\end{array}$ \\
\hline \multicolumn{2}{|c|}{ C. F. Sindt, W. R. Parrish } & 8. Performing Organ. Repure Wh. \\
\hline \multirow{2}{*}{\multicolumn{2}{|c|}{$\begin{array}{l}\text { 9. PI:REORAING ORGANIZATION NAME AND ADDRISSS } \\
\qquad \begin{array}{l}\text { NATIONAL BUREAU OF STANDARDS } \\
\text { DEPARTMENT OF COMMERCE } \\
\text { WASHINGTON, D.C. } 20234\end{array}\end{array}$}} & $\begin{array}{l}\text { 10. Pruject Task Wort Init Do. } \\
2750455\end{array}$ \\
\hline & & $\begin{array}{l}\text { 11. Contract (irant No.Y74-898, } \\
\text { Y75-808, Y75-S41, Y76-800 }\end{array}$ \\
\hline \multirow{2}{*}{\multicolumn{2}{|c|}{$\begin{array}{l}\text { 12. Spunsoring Organization Name and Complete Address (Street, City, State, ZIP) } \\
\text { Air Force Cambridge Research Laboratories } \\
\text { Air Force Systems Command } \\
\text { United States Air Force } \\
\text { Hanscom AFB, Massachusetts } 01731\end{array}$}} & $\begin{array}{l}\text { 13. Type of Report \& Perive } \\
\text { Covered } \\
\text { Final }\end{array}$ \\
\hline & & 14. Sponsoring Agency ( whe \\
\hline
\end{tabular}

\section{AI3STRACT (A 200-word or less factual summary of most sisnificant information. If document includes a significant bibliography or literature survey, mention it here.)}

This report covers the design and development of the prototype of a system to be used to fill a balloon that has been launched from an aircraft. The described system uses a hot packed bed heat exchanger to gasify $45.4 \mathrm{~kg}$ of liquid helium and warm the gas to $260 \mathrm{~K}$ for filling the balloon. The prototype system was successfully demonstrated on the ground by filling an ambient pressure balloon with $300 \mathrm{~m}^{3}$ of helium gas at an average temperature of $260 \mathrm{~K}$ in six minutes and 45 seconds.

17. KEY WORDS (six to twelve entries; alphabetical order; capitalize only the first letter of the first key word unless a proper name; separated by semicolons) Balloon; cryogenic balloon inflation; heat transfer; liquid helium; packed bed heat exchangers.

18. AVAILABILITY $\mathrm{X}$ Unlimited

For Official Distribution. Do Not Release to NTIS

Order From Sup. of Doc., U.S. Government Printing Office

Washington, D.C. 20402, SD Cat. No.C13

Y Order From National Technical Information Service (NTIS) Springfield, Virginia 22151

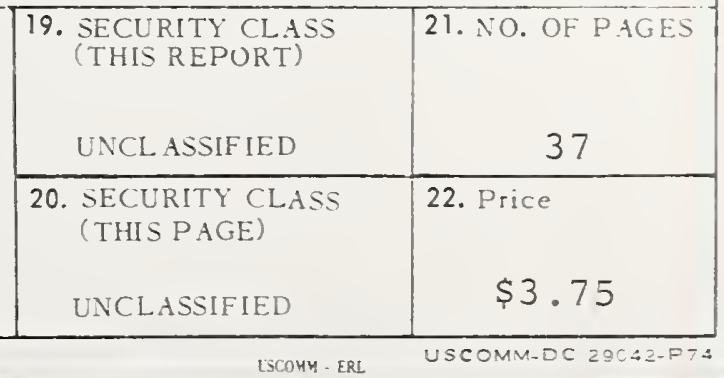


